\title{
Transcriptomes analysis reveals novel insight into the molecular mechanisms of somatic embryogenesis in Hevea brasiliensis
}

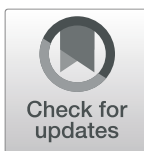

Ying Wang ${ }^{1+}$, Hui-Liang $\mathrm{Li}^{1+}$, Yong-Kai Zhou ${ }^{1,2+}$, Dong Guo ${ }^{1}$, Jia-Hong Zhu ${ }^{1}$ and Shi-Qing Peng ${ }^{1,3^{*}}$ (D)

\begin{abstract}
Background: Somatic embryogenesis (SE) is a promising technology for plant vegetative propagation, which has an important role in tree breeding. Though rubber tree (Hevea brasiliensis Muell. Arg.) SE has been founded, few late SE-related genes have been identified and the molecular regulation mechanisms of late SE are still not well understood.
\end{abstract}

Results: In this study, the transcriptomes of embryogenic callus (EC), primary embryo (PE), cotyledonary embryo (CE), abnormal embryo (AE), mature cotyledonary embryo (MCE) and withered abnormal embryo (WAE) were analyzed. A total of $887,852,416$ clean reads were generated, $85.92 \%$ of them were mapped to the rubber tree genome. The de novo assembly generated 36,937 unigenes. The differentially expressed genes (DEGs) were identified in the pairwise comparisons of CE vs. AE and MCE vs. WAE, respectively. The specific common DEGs were mainly involved in the phytohormones signaling pathway, biosynthesis of phenylpropanoid and starch and sucrose metabolism. Among them, hormone signal transduction related genes were significantly enriched, especially the auxin signaling factors (AUX-like1, GH3.1, SAUR32-like, IAA9-like, IAA14-like, IAA27-like, IAA28-like and ARF5-like). The transcription factors including WRKY40, WRKY70, MYBS3-like, MYB1R1-like, AlL6 and bHLH93-like were characterized as molecular markers for rubber tree late SE. CML13, CML36, CAM-7, SERK1 and LEAD-29-like were also related to rubber tree late SE. In addition, histone modification had crucial roles during rubber tree late SE.

Conclusions: This study provides important information to elucidate the molecular regulation during rubber tree late SE.

Keywords: Hevea brasiliensis, Somatic embryogenesis, RNA-seq, Hormone signal, Transcription factor, Histone modification

\footnotetext{
* Correspondence: shqpeng@163.com

†Ying Wang, Hui-Liang Li and Yong-Kai Zhou contributed equally to this work.

'Key Laboratory of Biology and Genetic Resources of Tropical Crops, Ministry of Agriculture, Institute of Tropical Bioscience and Biotechnology, Chinese Academy of Tropical Agricultural Sciences, No.4 Xueyuan Road, Haikou 571101, China

${ }^{3}$ Hainan Academy of Tropical Agricultural Resource, CATAS, Haikou 571101, China

Full list of author information is available at the end of the article
}

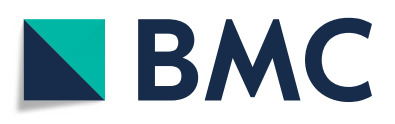

(c) The Author(s). 2021 Open Access This article is licensed under a Creative Commons Attribution 4.0 International License, which permits use, sharing, adaptation, distribution and reproduction in any medium or format, as long as you give appropriate credit to the original author(s) and the source, provide a link to the Creative Commons licence, and indicate if changes were made. The images or other third party material in this article are included in the article's Creative Commons licence, unless indicated otherwise in a credit line to the material. If material is not included in the article's Creative Commons licence and your intended use is not permitted by statutory regulation or exceeds the permitted use, you will need to obtain permission directly from the copyright holder. To view a copy of this licence, visit http://creativecommons.org/licenses/by/4.0/ The Creative Commons Public Domain Dedication waiver (http://creativecommons.org/publicdomain/zero/1.0/) applies to the data made available in this article, unless otherwise stated in a credit line to the data. 


\section{Background}

Rubber tree (Hevea brasiliensis Muell. Arg.), a tropical rubber-producing tree within the Euphorbiaceae family which is native to the great Amazonian basin of South America, is now widely cultivated to produce natural rubber in Southeast Asia [1]. Rubber tree is a perennial cross-pollination tree with a long juvenile period, which makes low efficiency of hybrid breeding [2]. Rubber tree is still propagated mostly by grafting, although the interaction between scion and rootstock of the grafted tree affects the growth, and natural rubber yield [3, 4].

Somatic embryogenesis (SE) is a promising and rapid vegetative propagation technique for plant regeneration. Plant regeneration via $\mathrm{SE}$ process in rubber tree had been established using different kinds of explants including immature anthers, internal integuments of immature fruits, inflorescence, as well as root [5-8]. The regenerated plants have juvenile characters and their own roots, which are called self-rooted juvenile clones (SRJCs). Compared with donor clones, SRJCs is superior in growth, rubber yield and stress resistance [9-11], which is a promising new rubber tree planting material in the future. There are two pathways (indirect primary SE, direct primary SE) to obtain primary somatic embryos [11]. Secondary SE allows to produce an unlimited number of secondary somatic embryos in a cyclic routine [10]. At present, the SE process is limited by irregular germination of the somatic embryos and low efficiency of plantlet recovery from somatic embryos [11], only a limited number of rubber tree genotypes can obtain regeneration plant [11-15].

To study the molecular regulation mechanisms of plant SE, the analyses of transcriptomes were carried out to identify SE related genes by RNA-seq in plant species, including herbaceous plants such as Arabidopsis [16], Gossypium hirsutum [17], maize [18], strawberry [19], rice [20], and woody plants such as Norway spruce [21], coconut plam [22], Brazilian pine [23], camphor tree [24], papaya [25], Dimocarpus longan [26] and so on. These studies demonstrated regulation mechanisms of SE at a molecular level, and several potential key genes were identified, such as genes encoding late embryogenesis abundant (LEA) protein [25], somatic embryogenesis receptor-like kinase (SERK) [27, 28], Leafy Cotyledon [28, 29], AGAMOUS-like 15 [30, 31], BBM (BABY BOOM) [28, 32], WUSCHEL [33, 34], and WUSCHEL homeobox 2 [28, 35].

SE of rubber tree can only be obtained for a limited number of genotypes [12-14]. Few studies have reported the molecular regulation mechanism of rubber tree SE. For example, Charbit et al. found that five cDNAs were differentially expressed in the embryogenic regenerating line could be enable an early diagnosis of friable rubber tree callus embryogenic potential, but the functions of these cDNAs haven't been identified [12]. Li et al. [36] found that three MADS-box genes (genes encode transcription factors that promote SE in many plant species [37-39]), were differentially expressed during rubber tree early embryogenesis, suggesting MADS-box genes involved rubber tree SE. Piyatraku et al. reported that 11 AP2/ERF genes might act as expression markers linked to the different stages of the somatic embryogenesis process in rubber tree [14]. Some studies have also shown that AP2/ERF genes play important roles in somatic embryogenesis as these genes involved in SE regulation [40-42]. However, the molecular regulation mechanisms of the late stage of rubber tree SE are still not well understood. To clarify whether the regenerate competence of different embryos depend on the genes during late $\mathrm{SE}$, we investigated the expression profiling using RNA-seq technology. This study will offer valuable information for the molecular regulation mechanisms of rubber tree late SE.

\section{Results}

Induction of somatic embryogenesis

The procedure of somatic embryogenesis and regeneration in $H$. brasiliensis was established (Fig. 1) as described previously [5]. The immature anthers were cultured in solid Murashige and Skoog (MS) medium supplemented with 2, 4-dichlorophenoxyacetic acid (2, 4 -D), kinetin (KT) and naphthylacetic acid (NAA) for 50 days. At the end of the period, the embryogenic calluses (ECs) were obtained. ECs were placed in the MS medium containing indole-3-acetic acid (IAA) and gibberellic acid $\left(\mathrm{GA}_{3}\right)$ for embryo induction. After 40 days, primary embryos (PEs) were collected. The PEs were transferred to MS medium containing 6-benzyl aminopurine (6-BA) and $\mathrm{AgNO}_{3}$ for growing. After 40 days, two different embryos based on their phenotype (cotyledonary embryo (CE), abnormal embryo (AE)) were observed in the culture medium.. We observed a significant difference between CEs and AEs in phenotype. The CEs and AEs were placed on half-strength MS medium containing IAA and BA. The CEs turned stronger into the mature cotyledonary embryo (MCE) 20 days later, whereas the AEs turned brown and grown up into withered abnormal embryo (WAE). After 30 days, the MCEs grew into complete seedlings, whereas the WAEs turned black and died. Based on the above phenotypic observation, six different samples during SE were selected for further study.

\section{Transcriptome analysis of rubber tree SE}

High-throughput sequencing generated 915,535,874 raw reads in $\mathrm{EC}, \mathrm{PE}, \mathrm{CE}, \mathrm{AE}, \mathrm{MCE}$ and $\mathrm{WAE}$ samples. A total of $887,852,416$ clean reads were retained by filtering the reads with adaptor sequences and ambiguous 


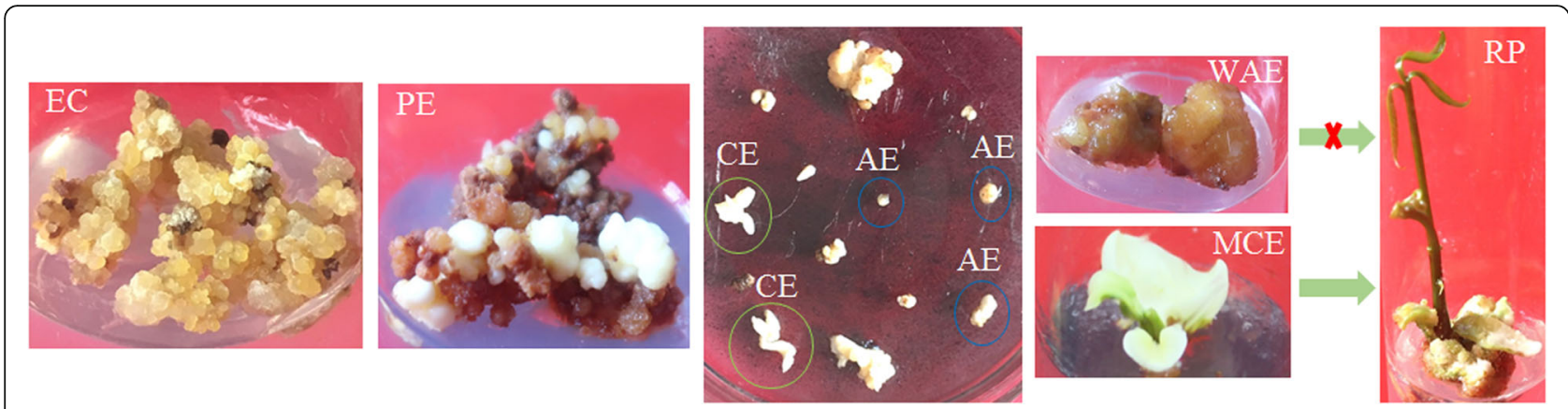

Fig. 1 The cultures during H. brasiliensis SE. EC: embryogenic callus; PE: primary embryo; CE: cotyledonary embryo; MCE: mature cotyledonary embryo; AE: abnormal embryo; WAE: withered abnormal embryo

"N" base. The percentage of quality score above 30 (Q30) was $97.92 \%$ and the GC percentage was $43 \%$ (Table 1). On average, $85.92 \%$ of the clean reads were mapped to $H$. brasiliensis genome.

All unigenes were annotated by the blast search against the public databases using BLASTx (E-value $-5 \leq$ 10). All 36,937 unigenes were annotated in 4 databases involved in the Clusters of Orthologous Groups of proteins (COG) database, the Gene Ontology (GO) database, the clusters of euKaryotic Orthologous Groups (KOG) database and the Evolutionary Genealogy of Genes: Non-supervised Orthologous Groups (eggNOG) database (Table 2). According to the COG functional classification, the 13,421 unigenes were categorized into 25 COG categories. The four most highly represented
COG categories were "general function prediction only" (20.57\%), "transcription" (11.75\%), "replication, recombination and repair" (11.53\%) and "signal transduction mechanisms" (10.51\%)(Fig. 2). In addition, 19,619, 20, 954 and 36,362 unigenes were successfully annotated in GO, KOG, eggNOG, respectively (Fig. S1, S2, S3).

\section{Global analysis of gene expression during rubber tree}

A Venn diagram was created to find the overlapped genes in the four different developmental stages of $H$. brasiliensis SE (Fig. 3a). A total of 25,841 genes overlapped in the four stages. Among them, 155 genes overlapped between EC and PE; 290 genes overlapped between PE and CE; 193 genes overlapped between CE and MCE. A total of 388, 297, 152 and 582 genes were

Table 1 Pre-processing statistics and quality control statistics

\begin{tabular}{|c|c|c|c|c|c|c|}
\hline Sample & Raw Reads & Clean Reads & Raw Bases (Gb) & Clean Bases (Gb) & Effective Rate (\%) & Q30 content (\%) \\
\hline EC-1 & $5.2 \mathrm{E}+07$ & $50,059,934$ & 7.86 & 7.56 & 96.21 & 94.81 \\
\hline EC-2 & $5.1 \mathrm{E}+07$ & $49,524,648$ & 7.73 & 7.48 & 96.73 & 94.81 \\
\hline EC-3 & $5.1 \mathrm{E}+07$ & $49,118,950$ & 7.68 & 7.42 & 96.61 & 94.78 \\
\hline PE-1 & $5 E+07$ & $48,319,634$ & 7.53 & 7.25 & 96.29 & 97.01 \\
\hline PE-2 & $5.1 \mathrm{E}+07$ & $49,061,282$ & 7.64 & 7.36 & 96.33 & 96.86 \\
\hline PE-3 & $5.1 \mathrm{E}+07$ & $48,891,852$ & 7.6 & 7.33 & 96.46 & 96.9 \\
\hline CE-1 & $5.1 \mathrm{E}+07$ & $49,805,096$ & 7.73 & 7.52 & 97.32 & 94.74 \\
\hline CE-2 & $5.2 \mathrm{E}+07$ & $50,906,314$ & 7.88 & 7.69 & 97.56 & 94.91 \\
\hline CE-3 & $5.1 \mathrm{E}+07$ & $50,054,842$ & 7.76 & 7.56 & 97.4 & 94.84 \\
\hline MCE-1 & $5.1 \mathrm{E}+07$ & $49,771,578$ & 7.7 & 7.47 & 96.96 & 95.89 \\
\hline MCE-2 & $5 E+07$ & $48,654,566$ & 7.54 & 7.3 & 96.85 & 94.92 \\
\hline MCE-3 & $5 E+07$ & $48,974,062$ & 7.52 & 7.35 & 97.72 & 95.62 \\
\hline$A E-1$ & $5 E+07$ & $48,881,230$ & 7.56 & 7.33 & 97.05 & 96.81 \\
\hline$A E-2$ & $5.1 \mathrm{E}+07$ & $48,970,492$ & 7.6 & 7.35 & 96.7 & 96.75 \\
\hline$A E-3$ & $5.1 \mathrm{E}+07$ & $48,844,568$ & 7.59 & 7.33 & 96.52 & 96.88 \\
\hline WAE-1 & $5.1 \mathrm{E}+07$ & $49,843,978$ & 7.71 & 7.53 & 97.67 & 94.71 \\
\hline WAE-2 & $5 \mathrm{E}+07$ & $49,076,246$ & 7.6 & 7.41 & 97.49 & 94.65 \\
\hline WAE-3 & $5 E+07$ & $49,093,144$ & 7.59 & 7.41 & 97.71 & 94.72 \\
\hline
\end{tabular}


Table 2 The number and distribution of unigenes annotated in the databases

\begin{tabular}{llll}
\hline Database & Annotated Number & $300<=$ length $<1000$ & length $>=1000$ \\
COG & 13,421 & 4142 & 9153 \\
GO & 19,619 & 5980 & 13,639 \\
KOG & 20,954 & 7547 & 13,097 \\
eggNOG & 36,362 & 14,578 & 21,038 \\
All & 36,937 & 14,983 & 21,176 \\
\hline
\end{tabular}

uniquely expressed in EC, PE, CE and MCE respectively. Another Venn diagram was also created to find the overlapped genes in the comparisons of PE, AE and CE of $H$. brasiliensis SE (Fig. 3b). As shown in Fig. 3b, 662 genes were exclusive to PE vs. AE. 1369 genes were exclusive to PE vs. CE. Moreover, 365 genes were found in AE vs. CE. To evaluate the differences of molecular response among all samples, the expression level of the unigenes was calculated by the expected number of Fragments Per Kilobase of transcript sequence per Million base pairs sequenced (FPKM). The top 20 expressed genes from EC, PE, CE and MCE libraries were shown in Table 3. Some of them including glutathione S-transferase (GST), lipid-transfer protein (LTP), peroxidase (POD), indole-3acetic acid-amido synthetase GH3.1, ADP-ribosylation factor, catalase isozyme, and polyubiquitin, were highly expressed in four stages.

In order to reveal the potential key factors and deeply understand the regulatory network of SE, the unigenes of each library of $H$. brasiliensis SE were compared under the condition of $-1.0 \geq \log _{2}$ [Fold Change (FC)] $\geq$ 1.0 and False Discovery Rate $(\mathrm{FDR})<0.01$. A total of 9415 DEGs were obtained in EC vs. PE, PE had 5260 up-regulated and 4155 down-regulated genes. In PE vs. CE, CE had 1483 genes up-regulated and 2366 genes down-regulated. In CE vs. MCE, 6449 DEGs were obtained, of which 4016 DEGs were up-regulated, whereas 2433 DEGs were down-regulated. The 2820 DEGs were found in PE vs. AE with 1300 up-regulated and 1520 down-regulated DEGs. In AE vs. WAE, 5590 DEGs were obtained, of which 3318 DEGs were up-regulated, whereas 2272 DEGs were down-regulated. In AE vs. CE, 1536 DEGs were found with 556 up-regulated and 980 down-regulated DEGs. The 3307 DEGs were found between WAE vs. MCE with 1938 up-regulated and 1369 down-regulated DEGs (Fig. 4).

\section{GO analysis of DEGs}

To further demonstrate the unigenes functions, GO assignments were carried out using the Blast2GO program. In AE vs. CE, 843 DEGs were classified into three major categories: biological processes (BP), cellular components (CC) and molecular function (MF). A total of $41 \mathrm{GO}$ subcategories were enriched over three major functional categories. The main subcategories are shown in Fig. 5a. The six major subcategories of BP were metabolic process, cellular process, single-organism process, biological regulation, localization and response to stimulus. The five major subcategories of $\mathrm{CC}$ were membrane,

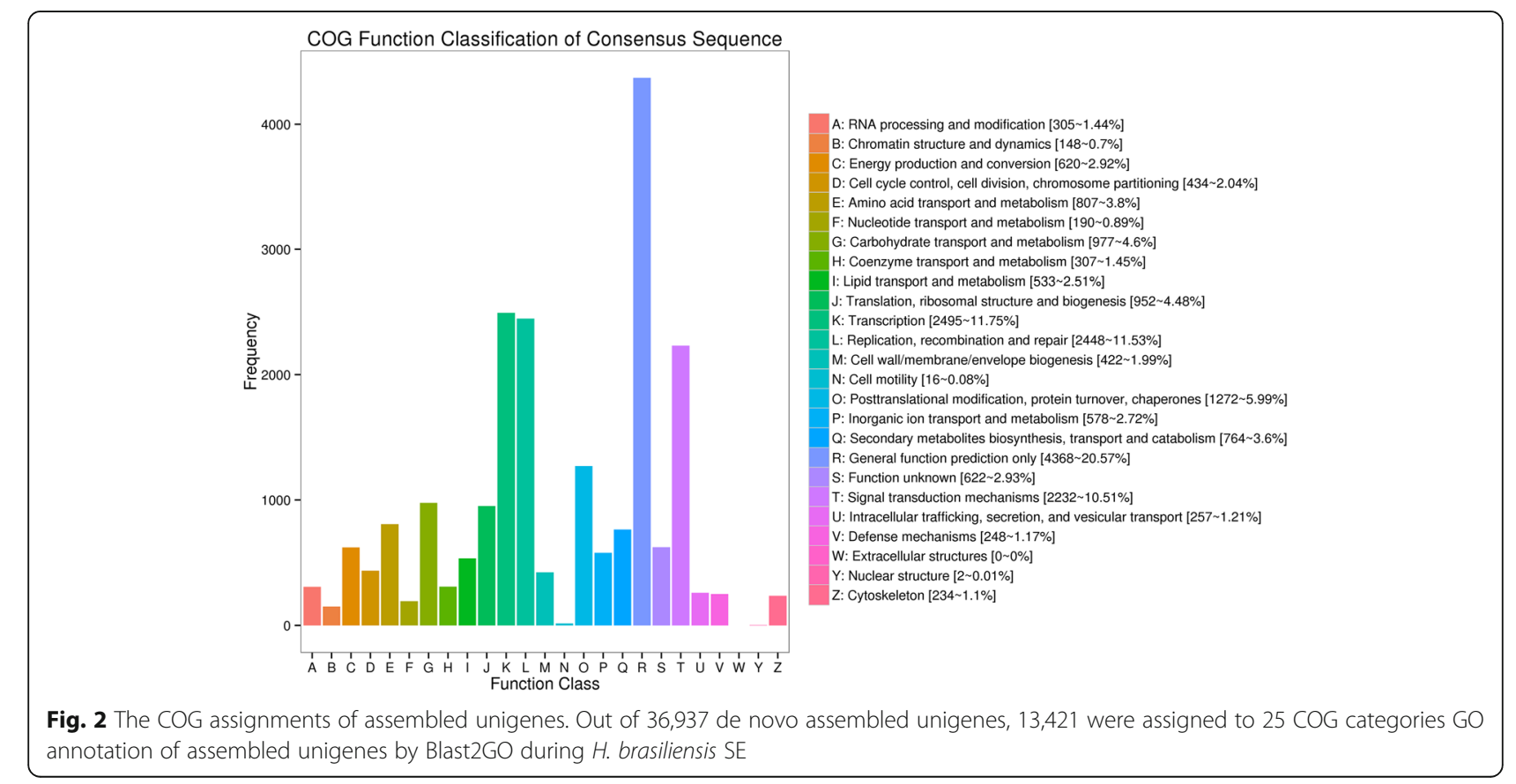



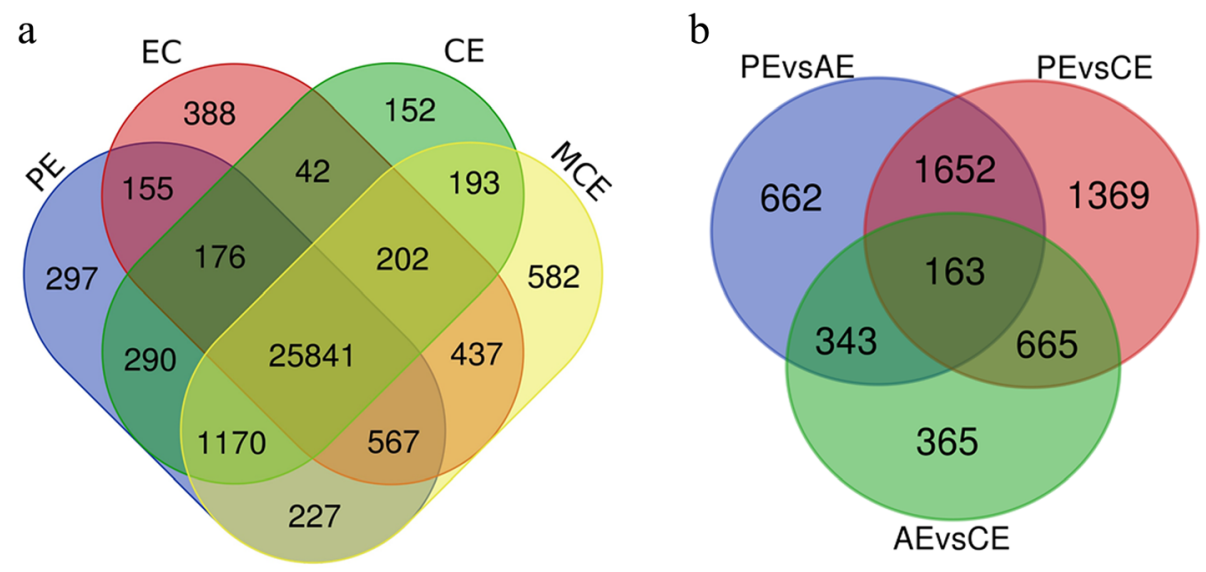

Fig. 3 Statistical analysis of the DEGs during SE stages. a The venn diagram of expressed genes in four developmental stages. b The venn diagram of expressed genes in PE vs. AE, PE vs. CE and CE vs. AE. EC: embryogenic callus; PE: primary embryo; CE: cotyledonary embryo; AE: abnormal embryo; MCE: mature cotyledonary embryo; WAE: withered abnormal embryo

cell, cell part, organelle and membrane part. The four major subcategories of MF were binding, catalytic activity, transporter activity and nucleic acid binding transcription factor activity. In WAE vs. MCE, 1927 DEGs were also classified into BP, CC and MF and subcategorized in 41 $\mathrm{GO}$ (Fig. 5b). The major subcategories of three categories were consistent with the result in $\mathrm{AE}$ vs. $\mathrm{CE}$.

\section{Kyoto encyclopedia of genes and genomes (KEGG) pathway of DEGs}

There were 376 DEGs in AE vs. CE, which were assigned to 46 KEGG pathways (Fig. 6a). The most representative pathways were phenylpropanoid biosynthesis (25 unigenes), plant hormone signal transduction (21 unigenes), starch and sucrose metabolism (20 unigenes), phenylalanine metabolism (19 unigenes), carbon metabolism (15 unigenes), biosynthesis of amino acid (14 unigenes) and glutathione metabolism (14 unigenes).

In WAE vs. MCE, the 771 DEGs were assigned to 57 KEGG pathways (Fig. 6b). The most represented pathways were phenylpropanoid biosynthesis (63 unigenes), starch and sucrose metabolism (49 unigenes), plant hormone signal transduction (46 unigenes), carbon metabolism (31 unigenes), photosynthesis (30 unigenes), phenylalanine metabolism (29 unigenes) and cyanoamino acid metabolism (29 unigenes). The results indicated that phenylpropanoid biosynthesis, phytohormones signaling pathway, and sucrose and starch metabolism played importance roles during $H$. brasiliensis late SE.

\section{Differential expression of hormone signal transduction related genes between $\mathrm{CE}$ and $\mathrm{AE}$}

Various phytohormones induced SE and regeneration in several plants have already been reported. For instance, auxin was used alone or in combination with other plant growth regulators on plant SE induction $[43,44]$. To further understand hormone regulation, FPKMs of hormonal signal transduction related genes were analyzed (Fig. 7a and Table S1). Among auxin signal transduction related genes, AUX-like5, IAA9-like, IAA28-like and GH3.1 were up-regulated in CE. SAUR71-like were highly expressed in AE than in CE. AUX22D-like, AUX28like, AUX-like1, AUX-like2, SAUR32-like, IAA14-like and IAA27-like were highly expressed in MCE. ARF5-like was lowly expressed in CE but highly expressed in MCE. These genes participated in the auxin signaling pathway, which was important for cell enlargement and plant growth (Fig. 7b).

Among abscisic acid (ABA) signal transduction related genes, PYL2-like was down-regulated in CE. PYL4-like was down-regulated in AE. Among jasmonic acid (JA) signal transduction related genes, JAZ7 was highly expressed in $\mathrm{CE}$ than in AE. JAZ5 was upregulated in AE. Among ethylene (ET) signal transduction related genes, $R A P 2-3$ was up-regulated in $\mathrm{CE}$ and in AE. RAP2-12-like and WRI1-like were highly expressed in CE. ERF4-like was up-regulated in MCE. ERF018-like was only up-regulated in AE. All the genes involved in the hormones signaling transduction pathways, including auxin, ABA, JA, ET, suggested that these hormones had an indispensable role in their complicated crosstalk process during $\mathrm{H}$. brasiliensis late SE. In vitro studies have suggested the role of various regulatory genes in embryogenic transition that are triggered by plant hormones [44]. The dynamic changes of these genes expression were critical for development of SEs. 
Table 3 The top 20 expressed genes in EC, PE, CE and MCE library

\begin{tabular}{|c|c|c|c|c|c|}
\hline & No & Gene-ID & Database-ID & FPKM-EC & Description \\
\hline \multirow[t]{20}{*}{ EC library } & 1 & gene10318 & XM_021818345.1 & 3266.37 & metallothionein-like protein type 2 \\
\hline & 2 & gene23077 & XM_021779607.1 & 2803.41 & probable indole-3-acetic acid-amido synthetase $\mathrm{GH} 3.1$ \\
\hline & 3 & gene24550 & XM_021781891.1 & 2587.98 & peptidyl-prolyl cis-trans isomerase-like \\
\hline & 4 & gene37167 & XM_021801099.1 & 5591.156667 & pathogenesis-related protein PR-4-like \\
\hline & 5 & gene41379 & XM_021807510.1 & 3354.676667 & metallothionein-like protein type 3 \\
\hline & 6 & gene41538 & XM_021807736.1 & 1336.78 & peroxidase 12-like \\
\hline & 7 & gene42156 & XM_021808475.1 & 3150.052519 & L-ascorbate peroxidase, cytosolic-like \\
\hline & 8 & gene548 & XM_021811448.1 & 1719.636667 & thioredoxin H-type-like \\
\hline & 9 & gene11066 & XM_021819455.1 & 1216.968149 & catalase isozyme 2 -like \\
\hline & 10 & gene1185 & XM_021821602.1 & 6138.533333 & metallothionein-like protein type 2 \\
\hline & 11 & gene15002 & XM_021825368.1 & 2578.13 & glucan endo-1,3-beta-glucosidase, basic isoform-like \\
\hline & 12 & gene18326 & XM_021830411.1 & 2459.693333 & endochitinase EP3-like \\
\hline & 13 & gene19193 & XM_021831939.1 & 1835.053335 & glutathione S-transferase F9-like \\
\hline & 14 & gene33311 & XM_021795239.1 & 1328.469977 & pathogenesis-related protein PR-4-like \\
\hline & 15 & gene3644 & XM_021801975.1 & 1588.716667 & thaumatin-like protein $1 \mathrm{~b}$ \\
\hline & 16 & gene41464 & XM_021807622.1 & 2882.38 & endochitinase EP3-like \\
\hline & 17 & gene5134 & XM_021810359.1 & 2157.947846 & catalase isozyme 2 \\
\hline & 18 & gene12558 & XM_021821637.1 & 1745.217667 & cysteine synthase \\
\hline & 19 & gene21974 & XM_021836019.1 & 1238.357898 & 40 S ribosomal protein S25-3-like \\
\hline & 20 & gene24408 & XM_021781690.1 & 1518.806667 & polyubiquitin \\
\hline \multirow[t]{20}{*}{ PE library } & 1 & gene17338 & XM_021828886.1 & 448.8675164 & ADP-ribosylation factor \\
\hline & 2 & gene24550 & XM_021781891.1 & 1090.893333 & peptidyl-prolyl cis-trans isomerase-like \\
\hline & 3 & gene25944 & XM_021784022.1 & 517.586 & polyubiquitin \\
\hline & 4 & gene37168 & XM_021801110.1 & 1051.049333 & pathogenesis-related protein PR-4-like \\
\hline & 5 & gene37235 & XM_021801218.1 & 424.1643333 & probable glutathione S-transferase \\
\hline & 6 & gene5278 & XM_021810573.1 & 700.6816667 & probable aquaporin TIP3-2 \\
\hline & 7 & gene548 & XM_021811448.1 & 651.8526667 & thioredoxin H-type-like \\
\hline & 8 & gene1185 & XM_021821602.1 & 691.8516667 & metallothionein-like protein type 2 \\
\hline & 9 & gene17500 & XM_021829184.1 & 651.8516667 & uncharacterized \\
\hline & 10 & gene19193 & XM_021831939.1 & 444.690335 & glutathione S-transferase F9-like \\
\hline & 11 & gene19425 & XM_021832135.1 & 4129.713333 & non-specific lipid-transfer protein 1-like \\
\hline & 12 & gene22222 & XM_021836400.1 & 475.7673333 & histone $\mathrm{H} 2 \mathrm{~B}$ \\
\hline & 13 & gene23940 & XM_021780963.1 & 563.119 & osmotin-like protein \\
\hline & 14 & gene37576 & XM_021801775.1 & 574.5693333 & thaumatin-like protein \\
\hline & 15 & gene12558 & XM_021821637.1 & 419.428 & cysteine synthase \\
\hline & 16 & gene35575 & XM_021798790.1 & 464.6649333 & copper transport protein ATX1-like \\
\hline & 17 & gene30702 & XM_021791318.1 & 1738.72 & peroxidase 42 -like \\
\hline & 18 & gene23545 & XM_021780391.1 & 2407.276667 & peroxidase 42 -like \\
\hline & 19 & gene33942 & XM_021796208.1 & 577.7063333 & peptidyl-prolyl cis-trans isomerase 1 \\
\hline & 20 & gene24408 & XM_021781690.1 & 472.838 & polyubiquitin \\
\hline \multirow[t]{4}{*}{ CE library } & 1 & gene17338 & XM_021828886.1 & 1145.143911 & ADP-ribosylation factor \\
\hline & 2 & gene18178 & XM_021830179.1 & 943.5483996 & protein translation factor SUI1 homolog 2-like \\
\hline & 3 & gene25944 & XM_021784022.1 & 1762.396667 & polyubiquitin \\
\hline & 4 & gene37168 & XM_021801110.1 & 9026.456667 & pathogenesis-related protein PR-4-like \\
\hline
\end{tabular}


Table 3 The top 20 expressed genes in EC, PE, CE and MCE library (Continued)

\begin{tabular}{|c|c|c|c|c|c|}
\hline & 5 & gene37235 & XM_021801218.1 & 2538.033333 & probable glutathione S-transferase \\
\hline & 6 & gene5278 & XM_021810573.1 & 1959.873667 & probable aquaporin TIP3-2 \\
\hline & 7 & gene5809 & XM_021811329.1 & 1199.044333 & metallothionein-like protein type 2 \\
\hline & 8 & gene7973 & XM_021814772.1 & 1108.26 & glutaredoxin \\
\hline & 9 & gene9140 & XM_021816591.1 & 4259.97 & metallothionein-like protein type 2 \\
\hline & 10 & gene17500 & XM_021829184.1 & 995.952 & uncharacterized \\
\hline & 11 & gene19425 & XM_021832135.1 & 3340.51 & non-specific lipid-transfer protein 1-like \\
\hline & 12 & gene20309 & XM_021833577.1 & 1361.93341 & ubiquitin-conjugating enzyme E2 28 \\
\hline & 13 & gene12558 & XM_021821637.1 & 1265.565333 & cysteine synthase \\
\hline & 14 & gene25797 & XM_021783808.1 & 1133.149667 & L-ascorbate peroxidase, cytosolic \\
\hline & 15 & gene30702 & XM_021791318.1 & 2923.166667 & peroxidase 42 -like \\
\hline & 16 & gene23545 & XM_021780391.1 & 3234.236667 & peroxidase 42 -like \\
\hline & 17 & gene24345 & XM_021781508.1 & 1190.793333 & translationally-controlled tumor protein homolog \\
\hline & 18 & gene36607 & XM_021800241.1 & 1155.013333 & aquaporin TIP1-1-like \\
\hline & 19 & gene41316 & XM_021807427.1 & 1017.603343 & aquaporin PIP1-3-like \\
\hline & 20 & gene31451 & XM_021792523.1 & 1867.496667 & probable aquaporin PIP1-2 \\
\hline \multirow[t]{20}{*}{ MCE library } & 1 & gene17338 & XM_021828886.1 & 1126.976 & ADP-ribosylation factor \\
\hline & 2 & gene18178 & XM_021830179.1 & 1004.106 & protein translation factor SUI1 homolog 2-like \\
\hline & 3 & gene25944 & XM_021784022.1 & 2101.800 & polyubiquitin \\
\hline & 4 & gene33318 & XM_021795235.1 & 1202.313 & pro-hevein \\
\hline & 5 & gene37168 & XM_021801110.1 & $18,664.897$ & pathogenesis-related protein PR-4-like \\
\hline & 6 & gene39161 & XM_021804156.1 & 918.860 & 2-methylbutanal oxime monooxygenase \\
\hline & 7 & gene41379 & XM_021807510.1 & 864.198 & metallothionein-like protein type 3 \\
\hline & 8 & gene41597 & XM_021807803.1 & 791.620 & elicitor-responsive protein 3-like \\
\hline & 9 & gene42156 & XM_021808475.1 & 2095.956 & L-ascorbate peroxidase, cytosolic-like \\
\hline & 10 & gene548 & XM_021811448.1 & 831.757 & thioredoxin H-type-like \\
\hline & 11 & gene9140 & XM_021816591.1 & 5217.597 & metallothionein-like protein type 2 \\
\hline & 12 & gene11066 & XM_021819455.1 & 1380.437 & catalase isozyme 2 -like \\
\hline & 13 & gene1185 & XM_021821602.1 & 1598.003 & metallothionein-like protein type 2 \\
\hline & 14 & gene19425 & XM_021832135.1 & 2686.840 & non-specific lipid-transfer protein 1-like \\
\hline & 15 & gene20309 & XM_021833577.1 & 1215.717 & ubiquitin-conjugating enzyme E2 28 \\
\hline & 16 & gene5134 & XM_021810359.1 & 1842.001 & catalase isozyme 2 \\
\hline & 17 & gene19423 & XM_021832115.1 & 1306.773 & non-specific lipid-transfer protein 1-like \\
\hline & 18 & gene23545 & XM_021780391.1 & 1473.353 & peroxidase 42 -like \\
\hline & 19 & gene24345 & XM_021781508.1 & 1151.487 & translationally-controlled tumor protein homolog \\
\hline & 20 & gene31451 & XM_021792523.1 & 821.413 & probable aquaporin PIP1-2 \\
\hline
\end{tabular}

\section{Differential expression of TFs and SE-related genes between $C E$ and $A E$}

Transcription factors (TFs) play important roles in hormone signaling and stress responses as multifunctional regulators in both zygotic embryo and SE. Some of these TFs have been used as markers of totipotency in plant species [45]. In the present study, we show that several TFs might play an important role during late SE of $H$. brasiliensis. In this regard, 219 TFs were identified. The following TFs families were overrepresented: WRKY,
MYB, MADS-box, AP2/ERF, bHLH. The expression profiles of 19 TFs in CE, AE, MCE and WAE are shown in Fig. 8a and Table S2. WRKY4O and WRKY70 were up-regulated in CE and down-regulated in AE. WRKY23 were highly expressed in AE than in CE. MYB26-like and MYB98-like were up-regulated in AE. MYBS3-like and MYB1R1-like were up-regulated in MCE. AGL11 and AGL15 were up-regulated in AE. BBM2 was highly expressed in AE. AIL6 was highly expressed in CE than in AE. bHLH93-like was highly expressed in CE. The 


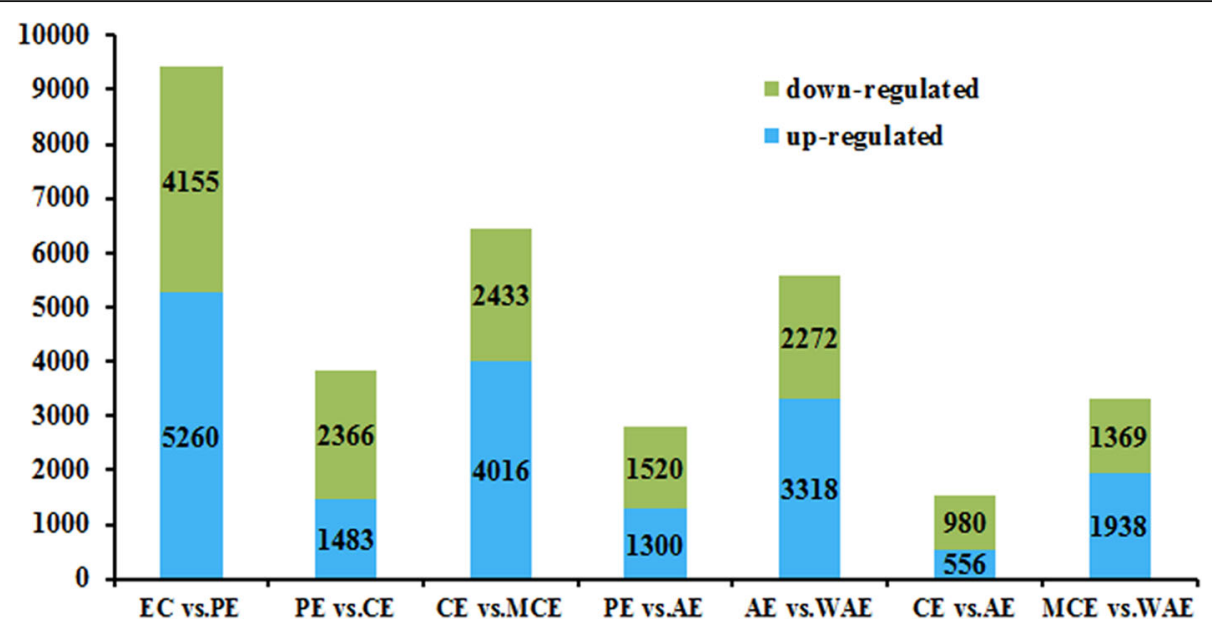

Fig. 4 The number of up- or down-regulated DEGs in $E C$ vs. $P E, P E$ vs. CE, CE vs. MCE, PE vs. AE, AE vs. WAE, CE vs. AE, MCE vs. WAE. EC: embryogenic callus; PE: primary embryo; CE: cotyledonary embryo; AE: abnormal embryo; MCE: mature cotyledonary embryo; WAE: withered abnormal embryo

expression of bHLH94-like was up-regulated in AE. The results implied these TFs may play a key role in $H$. brasiliensis late SE.

Some SE-related genes, such as CAM [46], SERK [47, 48], LEA [49, 50], have been identified to play a vital role during plant embryogenesis. CML13 and CML36 were up-regulated in CE but down-regulated in AE. CAM-5like and CAM (LOC110641724) were up-regulated in $\mathrm{AE}$ but had not changed in CE. CAM-7 was upregulated in CE but down-regulated in AE. SERK1 was up-regulated in CE. LEAD-34-like and SERK2-like showed higher expression in AE than in CE. LEAD-29like was up-regulated in MCE. The dynamic variation of the FPKM of these somatic embryogenesis-related genes suggested that they were critical for $H$. brasiliensis late SE.

\section{Differential expression of histone modifications related genes between $\mathrm{CE}$ and $\mathrm{AE}$}

The plant growth regulators and abiotic stress can contribute SE. In the meantime, these factors may induce epigenetic modifications [51]. Histone modification is one of the most important epigenetic modifications and plays a key role in the regulation of gene expression [52]. Therefore, the expression levels of histone modifiers were analyzed and shown in Fig. 8b and Table S3.

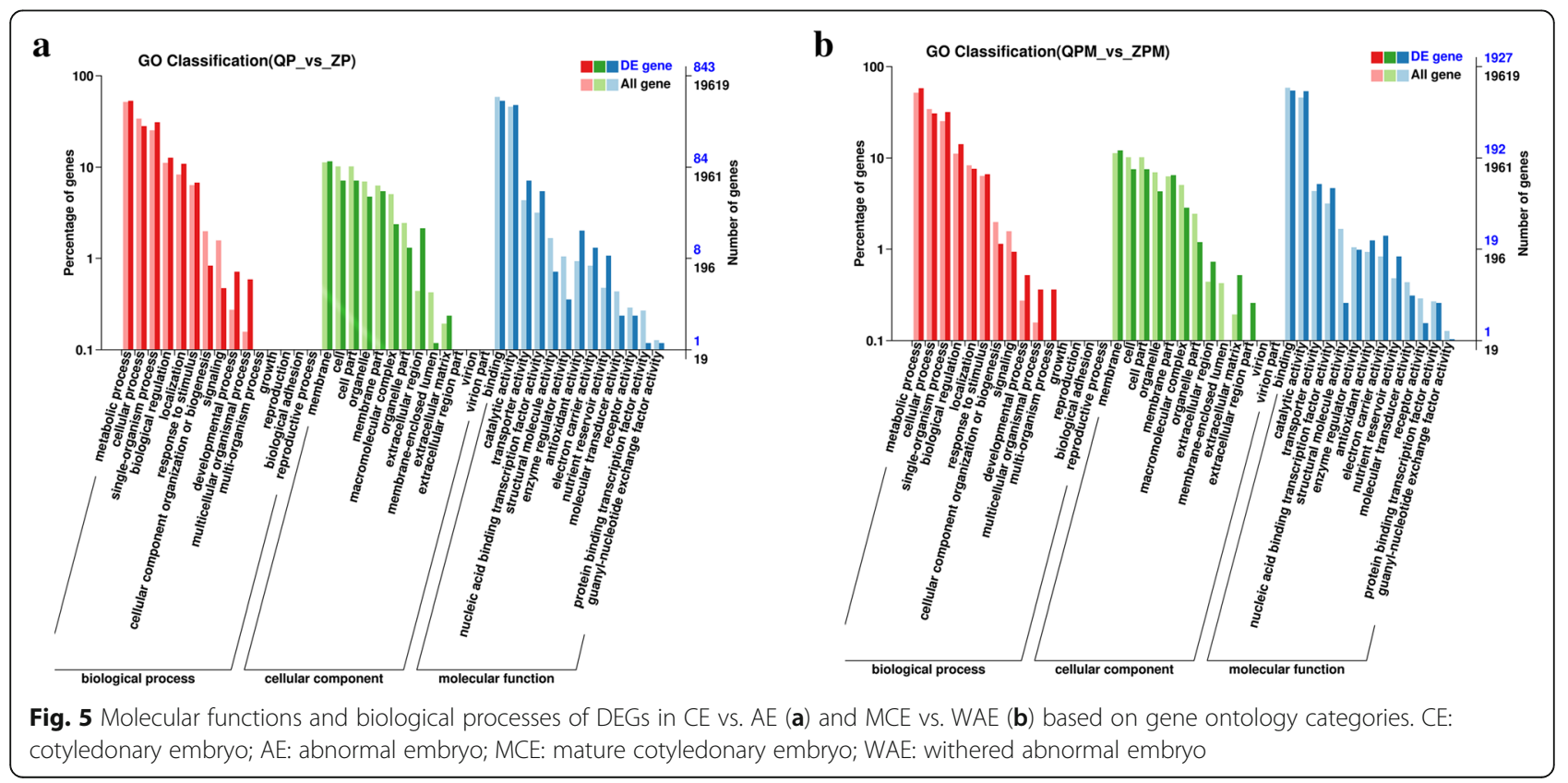




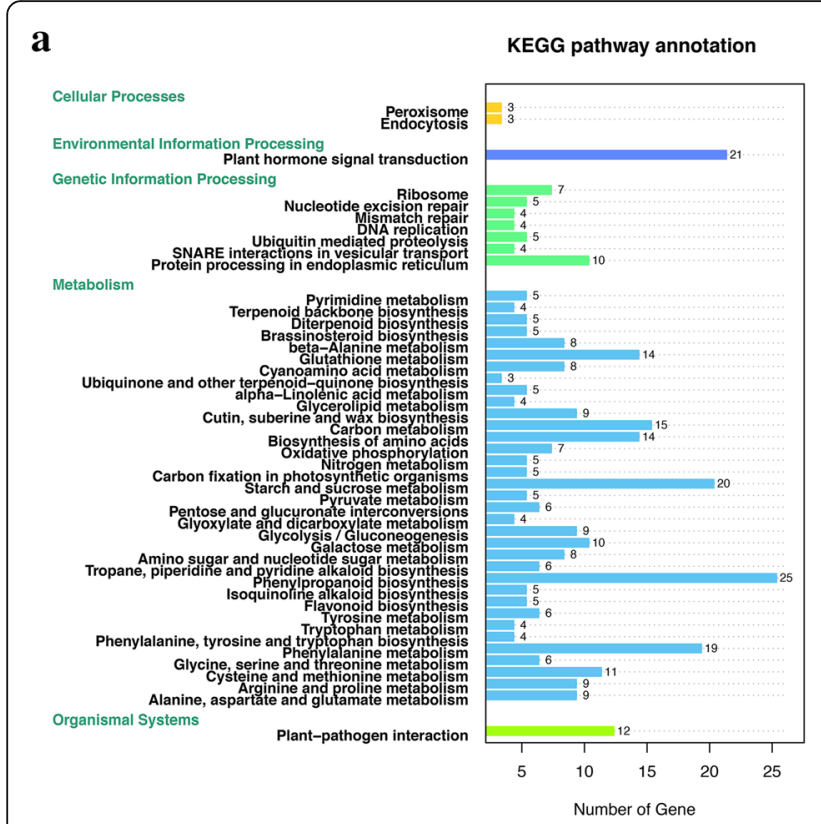

$\mathbf{b}$ KEGG pathway annotation

Fig. 6 KEGG annotation of DEGs in CE vs. AE (a) and MCE vs. WAE (b) based on gene ontology categories. CE: cotyledonary embryo; AE: abnormal embryo; MCE: mature cotyledonary embryo; WAE: withered abnormal embryo

CURLY LEAF (CLF), encoding one of polycomb repressive complex 2 (PRC2) catalytic subunit that repress gene expression through trimethylating histone $\mathrm{H} 3$ at lysine 27 (H3K27me3), was higher expression in $\mathrm{AE}$ than in CE. The histone H3 lysine 9 methyltransferase genes (SUVH1-like, SUVH3-like, SUVH4-like and SUVH9), SUVR3-like, EZA1-like and ASHH3-like were expressed at a higher level in CE. In addition, histone demethylation related genes, LSD1-homolog 1-like was highly expressed in CE. LSD1-homolog 2 was up-regulated in MCE. The increased expression of genes in CE or MCE suggested that it is likely to have a function during late SE.

The acetylation of histones is believed to promote open chromatin state and activate gene transcription.
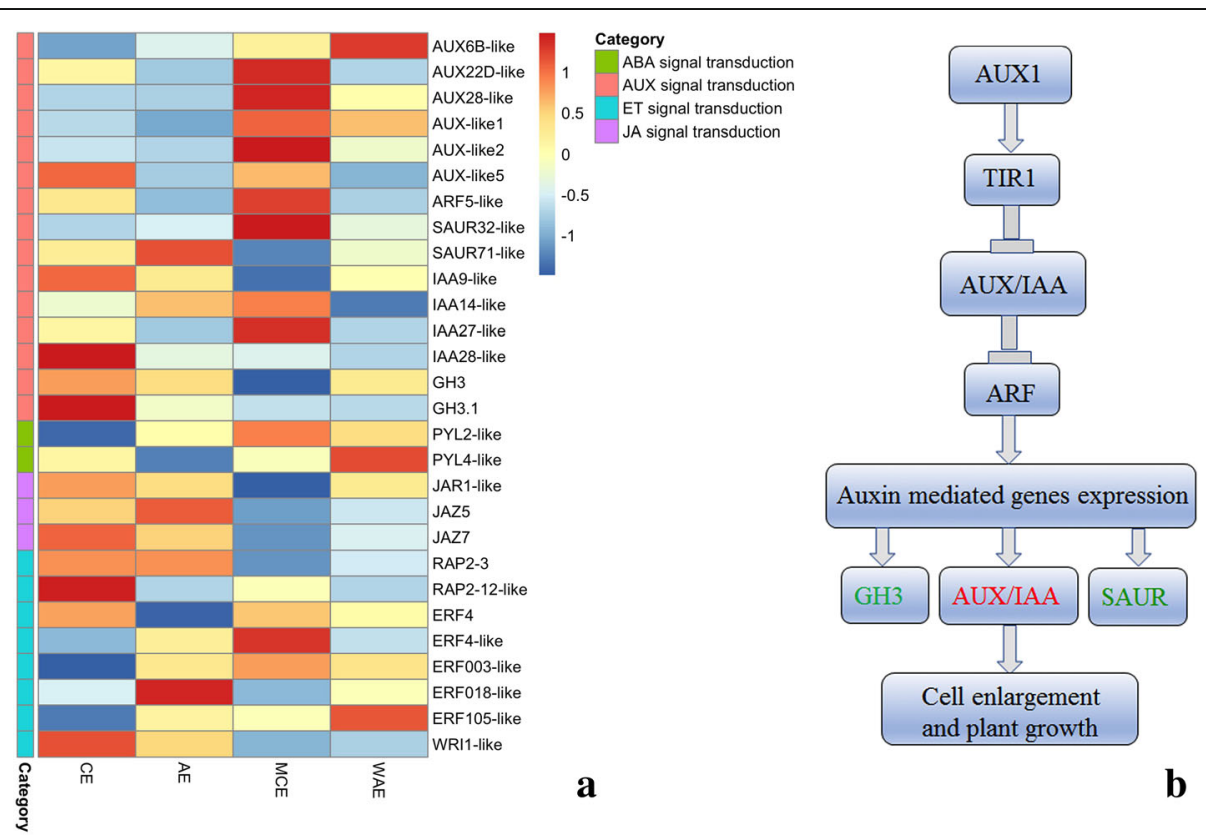

Fig. 7 Heatmap of the differentially expressed genes in hormonal signaling transduction (a) and putative pathway for AUX signaling (b). Heatmap indicate the gene expression level by Log 2 [FPKM] with a rainbow color scale. CE: cotyledonary embryo; AE: abnormal embryo; MCE: mature cotyledonary embryo; WAE: withered abnormal embryo 

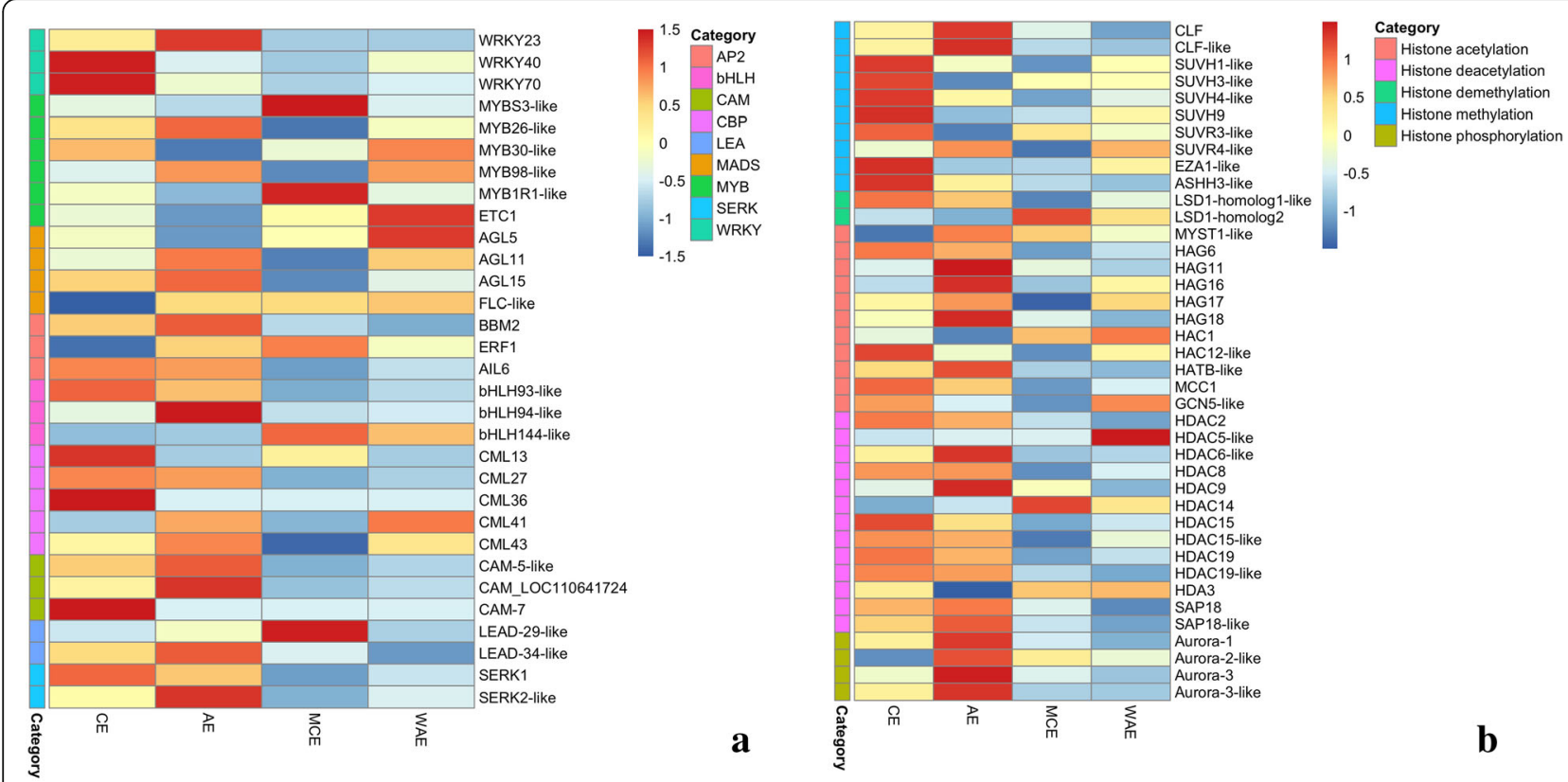

Fig. 8 Analysis of the differentially expressed genes in CE, AE, MCE and WAE. a Heatmap of the differentially expressed TFs and SE-related genes. b Heatmap of the differentially expressed in histone modifications. Heatmap indicate the gene expression level by Log 2 [FPKM] with a rainbow color scale. CE: cotyledonary embryo; AE: abnormal embryo; MCE: mature cotyledonary embryo; WAE: withered abnormal embryo

Ten of the eleven genes related to histone acetylation showed significant differential expression in CE vs. AE. HAG6, HAC12-like, MCC1 and GCN5-like were upregulated in CE. HAG11, HAG16, HAG18 and HATBlike were up-regulated in AE. 7 of the 13 genes related to histone deacetylation showed an obvious difference of expression in CE vs. AE. HDAC15-like and HDAC19 were highly expressed in CE. HDAC6-like, HDAC9 and SAP18-like were up-regulated in AE.

The histone phosphorylation related genes (Aurora-1, Aurora-2 like, Aurora-3 and Aurora-3 like) were highly expressed in AE than in CE. Plant Auroras can be divided into two categories according to the functions of Auroras. The alpha Auroras (Aurora 1 and Aurora 2) involve in controlling formative divisions throughout plant development. The beta Aurora (Aurora 3) associate with chromosome separation [53]. These genes highly expressed in AE can be used as candidate genes for indepth study in vitro embryogenesis.

\section{qPCR verification of selected DEGs}

To verify the reliability of transcriptome data, twenty genes related to SE were selected to carry out expression level analysis using qRT-PCR across 6 different tissues of $H$. brasiliensis (Fig. 9). Based on the transcriptome data analysis of $H$. brasiliensis SE, ARF4-like, GST, I2' $H$ like, PRX5-like, RBX1a-like, WRKY40 and WRKY70 were highly expressed in CE than in AE. E2 20-like, two EP3likes, ERF9-like, FLC-like, five H3.2 genes, H3.2-like, MYB98-like and U17-like were lowly expressed in CE than in AE. The $\mathrm{qPCR}$ results validated the expression levels of 19 genes which were highly consistent with transcriptome data.

\section{Discussion}

$\mathrm{SE}$ is a promising and rapid vegetative propagation technique for plant regeneration. However, the process of SE remains poorly understood and many factors impact upon competence for SE. Many problems need to be resolved and one of these could be a deep understanding of the molecular mechanisms involved either negatively o positively in the generation of the somatic embryos. The transcriptome analysis of plant SE revealed a large number of potential key factors of embryogenesis [25, 26, 54-56]. In longan early SE, 27 SE specific or preferential genes and 28 NEC (Non-embryogenic callus) preferential genes were characterized as molecular markers genes for longan early SE. The NEC-specific marker genes maybe the key inhibitor of the transition from NEC to EC, while the SE markers may function on SE development [26]. In this study, we obtained the transcriptome analysis of rubber tree SE derived from EC, PE, CE, AE, MCE and WAE. The de novo assembly generated 36,937 unigenes. We found the regenerate competence of $\mathrm{CE}$ and $\mathrm{AE}$ had obvious differences during late SE. Therefore, this study mainly focused on DEGs in CE vs. AE and MCE vs. WAE.

In $\mathrm{CE}$ vs. $\mathrm{AE}, 376 \mathrm{DEGs}$ were identified and assigned to 46 KEGG pathways. The 771 DEGs were also assigned to 57 KEGG pathways in MCE vs. WAE. The 


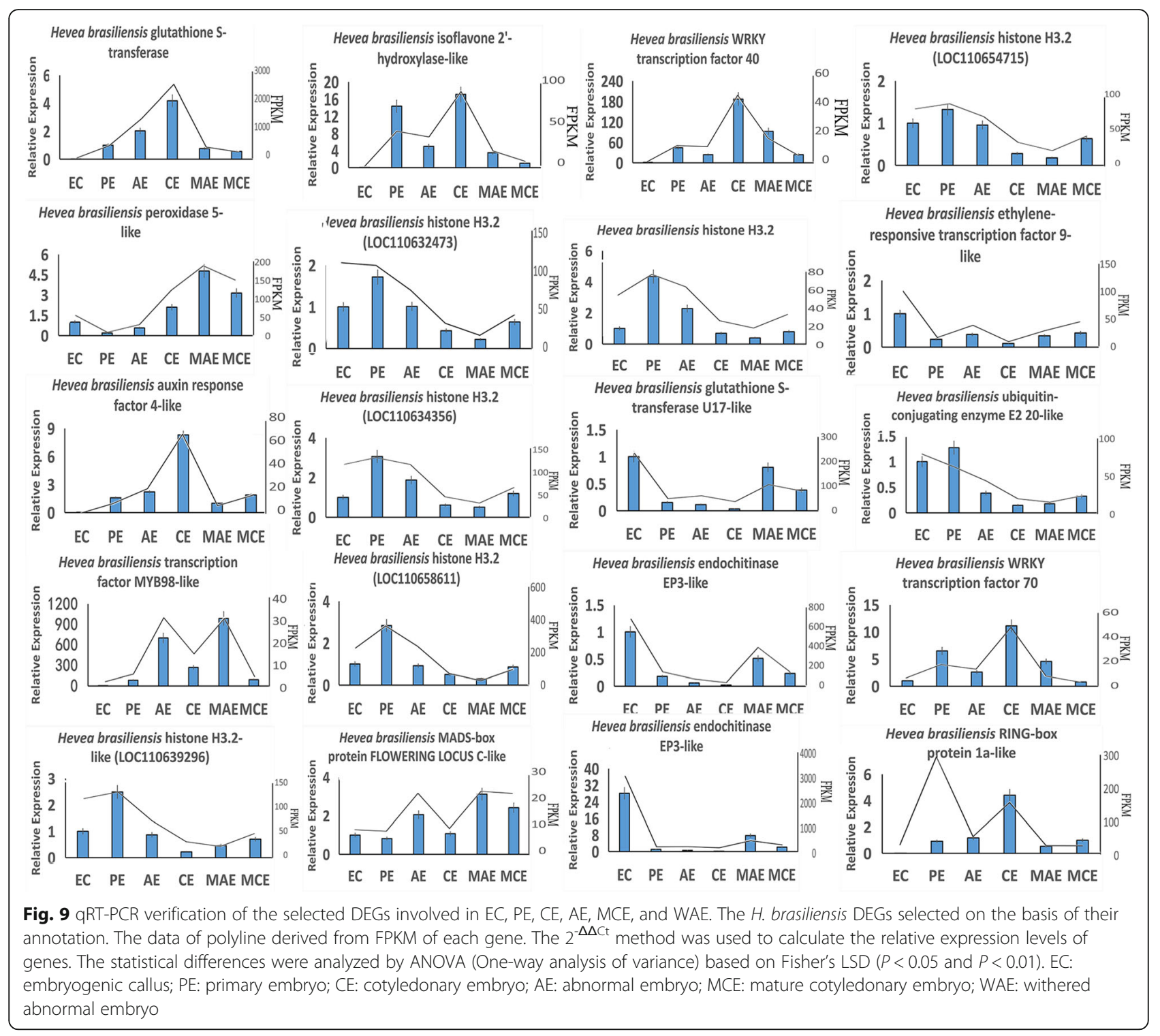

most representative pathways were phytohormones signaling pathway, biosynthesis of phenylpropanoid, and sucrose and starch metabolism in CE vs. AE and MCE vs. WAE. The significant role of phenylpropanoid biosynthesis in plant SE development has been studied, this pathway is associated with the tolerance of stress responses, probably through the reinforcement of the cell wall [57]. The phenylpropanoid biosynthesis-related genes were significantly enriched in papaya embryogenic callus [25] and in strawberry embryogenic callus [19]. In addition, external stimuli and plant hormones related genes played a key role in the SE process $[58,59]$. In longan early SE, plant hormones related genes were enriched, especially the cytokinin and auxin signaling components [26]. Moreover, signaling involved in sucrose and starch accumulation is essential for somatic embryogenetic development [60]. The nature of the carbohydrate supply can reflect the signaling networks that control development, including somatic embryogenesis [61]. Sucrose was added to the culture medium as exogenous carbon sources in conifers SE [62, 63]. The germination of Norway spruce (Picea abies) somatic embryos was affected by carbohydrates [64]. Endogenous carbohydrate status varies throughout the somatic embryogenesis of conifers [65], and can be used to identify cell lines with high-quality embryos [66, 67]. Genes involved in the three pathways can play important role in H. brasiliensis late SE.

Auxin is critical regulator in different developmental stages of SEs [68-70]. The addition of exogenous auxin can affect the expression level of endogenous IAA [59, 71-73]. Dynamic change of endogenous IAA has been proved to induce plant SE and improve SE competency [74]. Auxin/Indole-3-Acetic Acids (Aux/IAAs), Gretchen 
Hagen3s (GH3s), small auxin upregulated RNAs (SAURs) and auxin response factor (ARF) have been identified as auxin-responsive genes in auxin signaling and homeostasis [75-77], which can regulate downstream genes precisely and rapidly, and further regulated plant growth and developmental processes. Aux/IAA family plays a key role in inhibiting the expression levels of genes transcriptional activated by ARFs [78, 79]. In low auxin levels, Aux/IAA proteins interacted with ARFs and inhibited activation of auxin-responsive genes. In high auxin levels, these proteins can interact with transport inhibitor response 1/auxin signaling F-box (TIR1/AFB) receptors to be ubiquitinated and subsequently resolved by the $26 \mathrm{~S}$ proteasome [80-82]. The liberated ARFs regulated the expression of auxin-responsive genes (Fig. 7b). There were 29 Aux/IAA family members in Arabidopsis, but not all of them were induced by auxin [83]. Many Aux/IAA genes have also been identified in other plants, such as, Eucalyptus grandis [84], Solanum Lycopersicon [85], Cucumis sativus [86], Populus trichocarpa [87], Zea mays [88] and Oryza sativa [89, 90]. SAUR genes were consisted of a large multigene family, played crucial roles in regulating plant growth and development [91, 92]. GH3 family participated in a series of hormonedependent processes in plant, including root growth, and flowering $[93,94]$. In this study, high concentration of IAA and 2, 4-D were added in MS medium for inducing EC from immature male flowers. The concentration of IAA and 2, 4-D were reduced and withdrawal in the medium to trigger SE. This helps to slow down callus growth to induce embryo formation [95]. The transition was connected with changes in gene expression. Some $A U X / I A A$ family genes were highly expressed in CE or MCE. GH3.1 was up-regulated in CE. SAUR32-like and ARF5-like were up-regulated in MCE. These genes could be good gene expression markers and play a key role in the embryogenesis development process. In addition, JA and ET have also been reported to play a role in SE induction [96]. JAZ7, RAP2-12-like and WRI1-like were highly expressed in CE. The phytohormones signaling pathway related genes displayed intricate regulation during $\mathrm{H}$. brasiliensis late SE. The regulatory mechanisms of these genes in $H$. brasiliensis late SE will be confirmed in the future study.

Transcription factors are key factors in plant embryogenesis and development. Many studies on SE development showed that complicated transcription regulation networks maintaining embryogenic competency, and embryogenic callus formation [63, 97]. Some members of the WRKY TFs family genes can be stimulated by stress and are involved in carpel and ovule as well as in embryogenesis development $[98,99]$. Some WRKY genes have also been reported to be upregulated in embryogenic callus formation of bread wheat [54]. Transcriptome analysis showed that some WRKY genes are inducible in papaya and Arabidopsis thaliana embryogenic callus [25, 100]. In Panax ginseng, the expression of PgWRKY6 increased in SE process in response to 2, 4-D inducing. PgWRKY6 functioned in the development of embryogenic callus possibly through the signaling cross-link of auxins with reactive oxygen species in somatic embryogenesis [101]. These finds indicates WRKY TFs have crucial role in the process of somatic embryogenesis. To our best knowledge, there is no report on WRKY TFs regulating genes associated with SE. MYB family was also involved in plant development and growth [102-105], hormone signal transduction $[106,107]$. In this study, WRKY40, WRKY70, MYBS3-like and MYB1R1-like were highly expressed in $\mathrm{CE}$, suggesting that they might be used as marker genes for $H$. brasiliensis late SE. WRKY23, MYB26-like and MYB98-like were up-regulated in AE, indicating that these genes might act as negative modulators of SE. In addition, AtEMK, a member of the AP2/ERF family, was ectopically expressed and promotes the initiation of somatic embryos in Arabidopsis and H. brasiliensis [14, 108]. BBM had been reported as a marker in Brassica napus SE [109]. The over-expression of BBM can enhance SE and regeneration ability in tobacco, sweet pepper, cacao $[40,110$, 111]. The bHLH family is involved in developmental, growth, abiotic stress responses [112], and axillary meristem formation [63]. They also participate in abscisic acid and brassinosteroid signaling in Arabidopsis and rice [113]. A member of bHLH protein BIM1 regulated Arabidopsis SE and be involved in auxin and BR signaling pathways [114]. In this study, AIL6 and bHLH93-like were highly expressed in $\mathrm{CE}$, suggesting that they might play a key role in $H$. brasiliensis late SE. AGL11, AGL15, BBM2 and $b H L H 94-l i k e$ were up-regulated in AE, indicating that they have a negative regulatory role in late SE. To our knowledge, few transcription factors have been identified as negative modulators of plant SE. It will be of great interest to elucidate the function of these genes as negative modulators of SE. SERK has been proved as a key factor in plant SE. AtSERK1 was higher expression during Arabidopsis embryogenic formation [115]. SERK was abundant in embryogenic tissues in Dactylis glomerate [116]. However, SERKs were also tested in nonembryogenic tissues in maize, rice and wheat $[47,117$, 118]. $\mathrm{Ca}^{2+}$ has been identified to play a mediating role during plant SE $[46,119]$. LEA5, a late embryogenesis abundant proteins gene, was highly expressed in late embryogenesis [120]. In this study, SERK1, CML13, CML36 and CAM-7 were up-regulated in CE. LEAD-29-like were up-regulated in MCE. These genes can have various regulatory functions in $H$. brasiliensis late SE. LEAD34-like and SERK2-like werehighly expressed in $\mathrm{AE}$ than CE, implying that they acted as negative modulators of SE. Further investigation of regulatory 
machinery of these genes will be important in improving natural rubber SE.

The histone modifications played important roles in gene expression, DNA replication and transcription, chromatin compaction [121, 122]. Histone lysine methylations possessed the function of activating or derepressing transcription. H3K4, H3K36 and H3K79 methylations are associated with active transcription, whereas, H3K9, H3K27 and H4K20 methylations are involved in gene silencing [123]. H3K27me3 and H3K4me3 are the most frequent histone methylation marks. H3K27me3 is catalyzed by the trithorax-group (TrxG) and polycomb-group (PcG) proteins, of documented roles in regulating plant responses to environmental cues, cellular reprogramming, and plant stem cell maintenance [124]. The PcG proteins (PRC1 and PRC2), which cooperate to repress the genes via histone methylation during plant development [125]. In this study, CLF was higher expression in AE, suggesting H3K27me3 might inhibit the expression of genes associated with SE. Seven histone methylation related genes (SUVH1-like, SUVH3-like, SUVH4-like, SUVH9, SUVR3like, EZA1-like and ASHH3-like) were expressed at a higher level in CE. In addition, histone demethylation related genes, LSD1-homolog 1-like were highly expressed in CE. LSD1-homolog 2 were only up-regulated in MCE. KRYTONITE (KYP), encoding a histone H3 lysine 9 methyltransferase, also showed a higher expression level in Arabidopsis somatic embryos [16]. Some HATs including HAG1, HAF2, HAC1, HAC2, HAC4, HAC5 and HAC12 have been identified in Arabidopsis [16, 126, 127]. HAC2, HAG2 and HAG3 showed more accumulation in somatic embryos as compared to leaf tissues [16]. Similarly, in this study, histone acetylation related genes (HAG6, HAC12-like, MCC1 and GCN5-like) and histone deacetylation related genes (HDAC15-like, HDAC19) showed higher expression in CE. HDAC6-like, HDAC9 and SAP18-like were highly expressed in AE. HAC1 have been identified its function in reproductive and vegetative development [127]. HbHDA3 have been identified to interact with HbWRKY14 to regulate the expression of $H b S R P P$ [128]. It is possible that those histone modifications related genes may also have an important function in embryogenesis. However, detection of changed transcript levels for key genes involved in histone modification provides an indirect indication of changed histone modifications during SE. It is not clear whether the expression changes we observed are due to in vitro conditions (i.e. externally supplied auxin, stress responses) or changed histone modification signatures. Therefore, it will be of great interest to perform a global analysis of the epigenome architecture of somatic embryos in order to underlying the relationship of the expression of genes associated with SE and histone modification.

\section{Conclusions}

In this study, the transcriptome data for rubber tree SE were generated. A comparative analysis of gene expression profiles during rubber tree late SE identified a series of DEGs that regulated late SE in rubber tree. We revealed the expression level of some genes related to phytohormones signaling pathway such as auxin, JA and ET signaling pathway, implying their important roles in rubber tree embryogenesis development process. The transcription factors such as WRKY, MYB, AP2 and bHLH, as well as CAM, SERK and LEA that were related to rubber tree late $\mathrm{SE}$, might play a key role and become potential molecular marker genes in late SE. Histone modification might have crucial roles during late SE. This study provides novel insights into the molecular regulation mechanisms during rubber tree late SE.

\section{Methods}

Plant material and induction of somatic embryogenesis Plants of Hevea brasiliensis Muell. Arg. cultivar (reyan 7-33-97) were planted in National Rubber Tree Varieties Resource Garden of the Chinese Academy of Tropical Agriculture Sciences, Danzhou, Hainan, China.

Immature male flowers were gathered from the rubber tree of reyan7-33-37. Immature male flowers were surface-sterilized with $75 \%(\mathrm{v} / \mathrm{v})$ ethanol for $30 \mathrm{~s}$, and followed to immerse in $0.2 \%(\mathrm{v} / \mathrm{v})$ mercuric chloride solution for $10 \mathrm{~min}$, and then washed four times with distilled water. The immature anthers were cultured in solid MS medium containing $1 \mathrm{mgl}^{-1}$ 2,4-D, $1 \mathrm{mgl}^{-1}$ $\mathrm{KT}$ and $0.5 \mathrm{mg}^{-1} \mathrm{NAA}$. After an additional 5-6 weeks of growth, EC were obtained in the darkness and 26$28^{\circ} \mathrm{C}$. These samples of PE, CE, AE, MCE and WAE were collected successively. All samples were rapidly frozen in liquid nitrogen, and stored at $-80{ }^{\circ} \mathrm{C}$ until RNA extraction. Three biological replicates were prepared for each sample.

\section{Construction of CDNA library and sequencing}

Total RNA was extracted according to the instructions of RNAprep pure plant Kit (Polysaccharides and Poly phenolics-rich, QIAGEN). RNA degradation and contamination were monitored on $1 \%$ agarose gels. The quality of RNA was detected by using the NanoDrop 2000 spectrophotometer (IMPLEN, CA, USA). The mRNA was enriched from total RNA using magnetic beads containing Oligo (dT) and broken into small fragments. Transcriptome libraries were constructed according to the instructions of the Truseq ${ }^{\mathrm{m}}$ RNA sample preparation kit from Illumina (San Diego, CA). The library quality was examined using the Qsep100 Analyzer (BIOptic Inc., Taiwan, China). The cDNA libraries were deep sequenced on the Illumina novaseq6000 cDNA sequencing platform. 
Transcriptome de novo assembly and annotation

RNA seq data were quality controlled using SeqPrep (https://github.com/jstjohn/Seq-Prep) and Sickle (https://github.com/najoshi/sickle) with default parameters. Clean reads were acquired to remove the reads with adaptor sequences and ambiguous " $\mathrm{N}$ " base more than $1 \%$ and base quality less than Q15. All clean data were employed to do de novo assembly using Trinity (http://trinityrnaseq.sourceforge.net/). All unigenes were identified by searching the $H$. brasiliensis genome (GenBank under the accession code of LVXX01000000) from NCBI (https://www.ncbi.nlm.nih.gov/). All unigenes were searched against the COG (http://www.ncbi.nlm.nih. gov/COG), GO (http://geneontology.org/), KOG (http:// www.ncbi.nlm.nih.gov/structure/cdd/cdd.shtm) and eggNOG (http://eggnog5.embl.de/\#/app/home) databases using BLASTX (E-value-5 $\leq 10)$. BLAST2GO program (http://www.blast2go.com/b2ghome) was employed to get $\mathrm{GO}$ annotations of unique assembled unigenes for describing BP, MF and CC. The KEGG (https://www.kegg.jp) was to analyze metabolic pathway.

\section{Analysis of differentially expressed genes (DEGs)}

The expression level of the unigenes was calculated by FPKM. The FC represented the ratio of FPKM between two samples. The Benjamini-Hochberg correction method was adopted to correct the significance $P$-value obtained from the original hypothesis test. FDR was obtained by correcting the P-value of different significance. The genes with $-1.0 \geq \log _{2}[\mathrm{FC}] \geq 1.0$ and the threshold of FDR $<0.01$ were regarded as DEGs. A Venn diagram was created to find the overlapped DEGs in different developmental stages of $H$. brasiliensis SE using VennMaster as described previously [129].

\section{Expression profiles of genes in $\mathrm{H}$. brasiliensis SE}

FPKM was applied to analyze the gene expression level. The heat map was created using $\log _{2}$ [FPKM] with the pheatmap package [130].

\section{Quantitative PCR (qPCR)}

Twenty genes were chosen for validation by qPCR. The samples of EC, PE, CE, AE, MCE and WAE were used for RNA extraction, and then reverse transcribed into cDNA as template. Each sample included three biological replicates. qPCR specific primers for the twenty genes were designed by using Primer Premier software 6.0 (Table S4). HbACT7 was amplified as a standard control as described previously [131]. qPCR was performed on a Mx3005P Real-Time PCR system using a SYBR Premix EXTaq II ${ }^{\mathrm{TM}}$ Kit (TaKaRa, China). All reactions were performed at $95^{\circ} \mathrm{C}$ for $30 \mathrm{~s}, 40$ cycles at $95^{\circ} \mathrm{C}$ for $10 \mathrm{~s}, 58^{\circ} \mathrm{C}$ for $20 \mathrm{~s}$, and $72^{\circ} \mathrm{C}$ for $25 \mathrm{~s}$. The $2^{-\Delta \Delta \mathrm{Ct}}$ method was used to calculate the relative expression levels of genes [132]. The statistical differences were analyzed by ANOVA (One-way analysis of variance) based on Fisher's LSD test $(P<0.05$ and $P<0.01)$ [133].

\section{Abbreviations}

SE: Somatic embryogenesis; EC: Embryogenic callus; PE: Primary embryo; CE: Cotyledonary embryo; AE: Abnormal embryo; MCE: Mature cotyledonary embryo; WAE: Withered abnormal embryo; DEGs: Differentially expressed genes; SRJCs: Self-rooted juvenile clones; LEA: Late embryogenesis abundant protein; SERK: Somatic embryogenesis receptor-like kinase; BBM: BABY BOOM MS: Murashige and Skoog; 2,4-D: 2,4-Dichlorophenoxyacetic acid; KT: Kinetin; NAA: Naphthylacetic acid; IAA: Indole-3-acetic acid; GA3: Gibberellic acid; 6BA: 6-benzyl aminopurine; COG: Clusters of orthologous groups of proteins database; GO: Gene ontology; KOG: EuKaryotic orthologous groups; egg NOG: Non-supervised orthologous groups; KEGG: Kyoto encyclopedia of genes and genomes; FPKM: Fragments per kilo base of transcript sequence per million base pairs sequenced; GST: Glutathione S-transferase; LTP: Lipidtransfer protein; POD: Peroxidase; FC: Fold change; FDR: False discovery rate; BP: Biological process; CC: Cellular component; MF: Molecular function; cDNA: Complementary DNA; ABA: Abscisic acid; JA: Jasmonic acid; ET: Ethylene; TFs: Transcription factors; HATs: Histone acetyltransferases; qPCR: Quantitative polymerase chain reaction; Aux/IAAs: Auxin/indole-3-acetic acids; GH3s: Gretchen hagen3s; SAURs: Small auxin upregulated RNAs;

ARF: Auxin response factor; TIR1/AFB: Transport inhibitor response 1/ auxin signaling F-box; KYP: KRYTONITE; ANOVA: One-way analysis of variance; NEC: Non-embryogenic callus; ICpEC: Incomplete compact pro-embryogenic cultures; GE: Globular embryos

\section{Supplementary Information}

The online version contains supplementary material available at https://doi. org/10.1186/s12864-021-07501-9.

Additional file 1: Figure S1. GO function of classification of consensus. Additional file 2: Figure S2. KOG function of classification of consensus. Additional file 3: Figure S3. eggNOG function of classification of consensus.

Additional file 4: Table S1. FPKM and annotation of hormonal signal transduction related genes.

Additional file 5: Table S2. FPKM and annotation of TFs and SE-related genes.

Additional file 6: Table S3. FPKM and annotation of histone modifications related genes.

Additional file 7: Table S4 qRT-PCR Primer.

Acknowledgements

We thank the GENE DENOVO Technology Corporation (Guangzhou, China) for RNA-seq sequencing.

Authors' contributions

The study was conceived and directed by SQP. YW and SQP conducted the analysis and wrote the manuscript. YW, YKZ, HLL, DG and JHZ performed experiments and carried out the data analysis. All authors read and approved the final manuscript

Funding

This study was supported by the National Key R \& D Program of China (Grant No. 2018YFD1000502) and the National Natural Science Foundation of China (Grant No. 31670611, 31700269).

\section{Availability of data and materials}

The generated RNA-seq data have been deposited in NCBI-SRA database under the accession of PRJNA646309. The H. brasiliensis genome data used to annotate unigenes was downloaded from NCBI (GenBank under the accession codes of LVXX01000000). The annotation of the top 20 expressed genes in EC, PE, CE, and MCE library, histone modifications related genes, hormonal signal transduction related genes, TFs, and SE-related genes were 
deposited in the NCBI database. The accession numbers are included in Table 3 and Tables S1, S2, S3.

\section{Declarations}

\section{Ethics approval and consent to participate}

Not applicable.

\section{Consent for publication}

Not applicable.

\section{Competing interests}

The authors declare that they have no competing interests.

\section{Author details}

${ }^{1}$ Key Laboratory of Biology and Genetic Resources of Tropical Crops, Ministry of Agriculture, Institute of Tropical Bioscience and Biotechnology, Chinese Academy of Tropical Agricultural Sciences, No.4 Xueyuan Road, Haikou 571101, China. ${ }^{2}$ School of Life and Pharmaceutical Sciences, Hainan University, Haikou 570228, China. ${ }^{3}$ Hainan Academy of Tropical Agricultural Resource, CATAS, Haikou 571101, China.

Received: 15 July 2020 Accepted: 2 March 2021

Published online: 12 March 2021

\section{References}

1. Priyadarshan PM, Goncalves PS. Hevea gene pool for breeding. Genet Resour Crop Evol. 2003;50:101-14.

2. Clément-Demange A, Priyadarshan P, Hoa TT, Venkatachalam P. Hevea rubber breeding and genetics. Plant Breeding Rev. 2007:29:177.

3. Ahmad B. Effect of rootstock on growth and water use efficiency of Heved during water stress. J Rubber Res. 1999;2:99-119.

4. Sobhana P, Gopalakrishnan J, Jacob J, Sethuraj MR. Physiological and biochemical aspects of stock-scion interaction in Hevea brasiliensis. Indian Nat Rubber Res. 2001;14:131-6.

5. Wang ZY, Zeng XS, Chen CQ, Wu HY, Li OY, Fan GJ, Lu WJ. Induction of rubber plantlets from anther of Hevea brasiliensis Muell. Arg. in vitro. Chinese J Trop. Crops. 1980;1:25-6.

6. Carron MP, Enjalric F. Studies on vegetative micropropagation of Hevea brasiliensis by somatic embryogenesis and in vitro microcutting. In: A. Fujiwara (ed.). Plant Tissue Culture.1982; 751-752.

7. Sushamakumari S, Sobha S, Rekha K, Jayasree R, Asokan MP. Influence of growth regulators and sucrose on somatic embryogenesis from immature inflorescence of Hevea brasiliensis (Muell. Arg.). Indian J Nat Rubber Res. 2000:13:19-29.

8. Zhou QN, Jiang ZH, Huang TD, Li WG, Sun AH, Dai XM, Li Z. Plant regeneration via somatic embryogenesis from root explants of Hevea brasiliensis. Afr J Biotechnol. 2010:9:8168-73.

9. Yang SQ, Mo YY. Some physiological propeptries of latex from somatic plants of Hevea brasiliensis. Chinese J Trop Crops. 1994;15:13-20.

10. Yuan XH, Yang SQ, Xu LY, Wu JL, Hao BZ. Characteristics related to higher rubber yield of Hevea brasiliensis juvenile-type clone Gl1. J Rubber Res. 1998; 1:125-32.

11. Mignon $E$, Werbrouck S. Somatic embryogenesis as key technology for shaping the rubber tree of the future. Front Plant Sci. 2018;9:1804

12. Charbit $\mathrm{E}$, Legavre $\mathrm{T}$, Lardet $\mathrm{L}$, Bourgeois $\mathrm{E}$, Ferrière N, Carron MP. Identification of differentially expressed cDNA sequences and histological characteristics of Hevea brasiliensis calli in relation to their embryogenic and regenerative capacities. Plant Cell Rep. 2004;22:539-48.

13. Lardet L, Dessailly F, Carron MP, Montoro P, Monteuuis O. Influences of aging and cloning methods on the capacity for somatic embryogenesis of a mature Hevea brasiliensis genotype. Tree Physiol. 2009;29:291-8.

14. Piyatrakul P, Putranto RA, Florence Martin F, Rio M, Dessailly F, Leclerca J, Dufayard JF, Lardet L, Montoro P. Some ethylene biosynthesis and AP2/ERF genes reveal a specific pattern of expression during somatic embryogenesis in Hevea brasiliensis. BMC Plant Biol. 2012;12:244.

15. Lardet L, Martin F, Dessailly F, Carron MP, Montoro P. Effect of exogenous calcium on post-thaw growth recovery and subsequent plant regeneration of cryopreserved embryogenic calli of Hevea brasiliensis (Muell. Arg.). Plant Cell Rep. 2007;26:559-69.
16. Wickramasuriya AM, Dunwell JM. Global scale transcriptome analysis of Arabidopsis embryogenesis in vitro. BMC Genomics. 2015;16:301.

17. Jin FY, Hu LS, Yuan DJ, Xu J, Gao WH, He LR, Yang XY, Zhang XL. Comparative transcriptome analysis between somatic embryos (SEs) and zygotic embryos in cotton: evidence for stress response functions in SE development. Plant Biotechnol J. 2014;12:161-73.

18. Salvo SA, Hirsch CN, Buell CR, Kaeppler SM, Kaeppler HF. Whole transcriptome profiling of maize during early somatic embryogenesis reveals altered expression of stress factors and embryogenesis-related genes. PLoS One. 2014;9:e111407.

19. Gao LM, Zhang J, Hou Y, Yao YC, Ji QL. RNA-seq screening of differentiallyexpressed genes during somatic embryogenesis in Fragaria $x$ ananassa Duch. 'Benihopp'. J Hortic Sci Biotechnol. 2015;90:671-81.

20. Indoliya Y, Tiwari P, Chauhan AS, Goel R, Shri M, Bag SK, Chakrabarty D. Decoding regulatory landscape of somatic embryogenesis reveals differential regulatory networks between japonica and indica rice subspecies. Sci Rep. 2016:6:23050.

21. Yakovlev IA, Carneros E, Lee Y, Olsen JE, Fossdal CG. Transcriptional profiling of epigenetic regulators in somatic embryos during temperature induced formation of an epigenetic memory in Norway spruce. Planta. 2016;243: 1237-49.

22. Rajesh MK, Fayas TP, Naganeeswaran S, Rachana KE, Bhavyashree U, Sajini KK, Karun A. De novo assembly and characterization of global transcriptome of coconut palm (Cocos nucifera L.) embryogenic calli using Illumina paired end sequencing. Protoplasma. 2016;253:913-28.

23. Elbl P, Lira BS, SCS A, Jo L, ALW DS, Coutinho LL, EIS F, Rossi M. Comparative transcriptome analysis of early somatic embryo formation and seed development in Brazilian pine, Araucaria angustifolia (Bertol.) Kuntze. Plant Cell Tiss Org Cult. 2015;120:903-15.

24. Shi XP, Zhang CJ, Liu QH, Zhang Z, Zheng B, Bao MZ. De novo comparative transcriptome analysis provides new insights into sucrose induced somatic embryogenesis in camphor tree (Cinnamomum camphora L.). BMC Genomics. 2016;17:26

25. Jamaluddin ND, Mohd Noor N, Goh H. Genome-wide transcriptome profiling of Carica papaya L. embryogenic callus. Physiol Mol Biol Plants. 2017;23:357-68

26. Chen Y, Xu X, Liu Z, Zhang Z, Han X, Lin Y, Lai Z. Global scale transcriptome analysis reveals differentially expressed genes involve in early somatic embryogenesis in Dimocarpus longan Lour. BMC Genomics. 2020;21:4

27. Savona M, Mattioli R, Nigro S, Falasca G, Della Rovere F, Costantino P, De Vries S, Ruffoni B, Trovato M, Altamura MM. Two SERK genes are markers of pluripotency in Cyclamen persicum mill. J Exp Bot. 2012;63:471-88.

28. Rupps A, Raschke J, Rümmler M, Linke B, Zoglauer K. Identification of putative homologs of Larix decidua to BABYBOOM (BBM), LEAFY COTYLEDON1 (LEC1), WUSCHEL-related HOMEOBOX2 (WOX2) and SOMATIC EMBRYOGENESIS RECEPTOR-like KINASE (SERK) during somatic embryogenesis. Planta. 2016:243:473-88.

29. Gaj MD, Zhang S, Harada JJ, Lemaux PG. Leafy cotyledon genes are essential for induction of somatic embryogenesis of Arabidopsis. Planta. 2005;222:977-88.

30. Thakare D, Tang W, Hill K, Perry SE. The MADS-domain transcriptional regulator AGAMOUS-LIKE15 promotes somatic embryo development in Arabidopsis and soybean. Plant Physiol. 2008;146:1663-72.

31. Zheng Q, Zheng Y, Perry SE. AGAMOUS-Like15 promotes somatic embryogenesis in Arabidopsis and soybean in part by the control of ethylene biosynthesis and response. Plant Physiol. 2013;161:2113-27.

32. Horstman A, Li M, Heidmann I, Weemen M, Chen B, Muiño JM, Angenent GC, Boutilier K. The BABY BOOM transcription factor activates the LEC1-ABI3FUS3-LEC2 network to induce somatic embryogenesis. Plant Physiol. 2017; 2175:848-57.

33. Bouchabké-Coussa O, Obellianne M, Linderme D, Montes E, Maia-Grondard A, Vilaine F, Pannetier C. Wuschel overexpression promotes somatic embryogenesis and induces organogenesis in cotton (Gossypium hirsutum L.) tissues cultured in vitro. Plant Cell Rep. 2013:32:675-86.

34. Zheng Q, Perry SE. Alterations in the transcriptome of soybean in response to enhanced somatic embryogenesis promoted by orthologs of Agamouslike15 and Agamous-like18. Plant Physiol. 2014;164:1365-77.

35. Tvorogova VE, Lebedeva MA, Lutova LA. Expression of WOX and PIN genes during somatic and zygotic embryogenesis in Medicago truncatula. Russ J Genet. 2015:51:1189-98. 
36. Yang Z, Li C, Wang Y, Zhang C, Wu Z, Zhang X, Liu C, Li F. GhAGL15s, preferentially expressed during somatic embryogenesis, promote embryogenic callus formation in cotton (Gossypium hirsutum L.). Mol Genet Genomics. 2014;289:873-83.

37. Zheng Q, Perry SE. Alterations in the transcriptome of soybean in response to enhanced somatic embryogenesis promoted by orthologs of Agamouslike15 and Agamous-like18. Plant Physiol. 2014;164:1365-77.

38. Zheng Q, Zheng Y, Ji H, Burnie W, Perry SE. Gene regulation by the AGL15 transcription factor reveals hormone interactions in somatic embryogenesis. Plant Physiol. 2016;172:2374-87.

39. Li HL, Wang Y, Guo D, Tian WM, Peng SQ. Three MADS-box genes of Hevea brasiliensis expressed during somatic embryogenesis and in the laticifer cells. Mol Biol Rep. 2011;38:4045-52.

40. Srinivasan C, Liu Z, Heidmann I, EDJ S, Fukuoka H, Joosen R, Lambalk J, Angenent G, Scorza R, JBM C, Boutilier K. Heterologous expression of the BABY BOOM AP2/ERF transcription factor enhances the regeneration capacity of tobacco (Nicotiana tabacum L.). Planta. 2007;225:341-51.

41. Mantiri FR, Kurdyukov S, Lohar DP, Sharopova N, Saeed NA, Wang XD, Vandenbosch KA, Rose RJ. The transcription factor MtSERF1 of the ERF subfamily identified by transcriptional profiling is required for somatic embryogenesis induced by auxin plus cytokinin in Medicago truncatula. Plant Physiol. 2008;146:1622-36.

42. Mantiri FR, Kurdyukov S, Chen SK, Rose RJ. The transcription factor MtSERF1 may function as a nexus between stress and development in somatic embryogenesis in Medicago truncatula. Plant Signal Behav. 2008;3:498-500.

43. Gaj MD. Factors influencing somatic embryogenesis induction and plant regeneration with particular reference to Arabidopsis thaliana (L.) Heynh. Plant Growth Regul. 2004;43:27-47.

44. Ikeuchi M, Ogawa Y, Iwase A, Sugimoto K. Plant regeneration: cellular origins and molecular mechanisms. Development. 2016;143:1442-4451.

45. Mahdavi-Darvari F, Noor NM, Ismanizan I. Epigenetic regulation and gene markers as signals of early somatic embryogenesis. Plant Cell Tiss Organ Cult. 2015;120:407-22.

46. Kiselev KV, Shumakova OA, Manyakhin AY, Mazeika AN. Influence of calcium influx induced by the calcium ionophore, A23187, on resveratrol content and the expression of CDPK and STS genes in the cell cultures of Vitis amurensis. Plant Growth Regul. 2012;68:371-81.

47. Ito Y, Takaya K, Kurata N. Expression of SERK family receptor-like protein kinase genes in rice. BBA-Gene Struct Expre. 1730;2005:253-358.

48. Singla B, Khurana JP, Khurana P. Structural characterization and expression analysis of the SERK/SERL gene family in rice (Oryza sativa). Int J Plant Genomics. 2009:10:1-8.

49. Hundertmark M, Hincha DK. LEA (late embryogenesis abundant) proteins and their encoding genes in Arabidopsis thaliana. BMC Genomics. 2008;9:118.

50. Kikawada T, Nakahara Y, Kanamori Y, Iwata K, Watanabe M, McGee B, Tunnacliffe A, Okuda T. Dehydration-induced expression of LEA proteins in an anhydrobiotic chironomid. Biochem Biophys Res Comm. 2006;348:56-61.

51. Miguel C, Marum L. An epigenetic view of plant cells cultured in vitro: Somaclonal variation and beyond. J Exp Bot. 2011;62:3713-25.

52. Berr A, Shafiq S, Shen WH. Histone modifications in transcriptional activation during plant development. Biochim Biophys Acta. 1809;2011:567-76.

53. BoruC J, Weimer AK, Stoppin-Mellet V, Mylle E, Kosetsu K, Cedeño C, Jaquinod M, Njo M, De Milde L, Tompa P, Gonzalez N, Inzé D, Beeckman T, Vantard M, Van Damme D. Phosphorylation of MAP 65-1 by arabidopsis aurora kinases is required for efficient cell cycle progression. Plant Physiol. 2017;173:582-99.

54. Chu ZL, Chen JY, Sun JY, Dong ZD, Yang X, Wang Y, Xu HX, Zhang XK, Chen F, Cui DQ. De novo assembly and comparative analysis of the transcriptome of embryogenic callus formation in bread wheat (Triticum aestivum L.). BMC Plant Biol. 2017;17:244.

55. Guo HH, Guo HX, Zhang L, Tang ZM, Yu XM, Wu JF, Zeng FC. Metabolome and transcriptome association analysis reveals dynamic regulation of purine metabolism and flavonoid synthesis in trans differentiation during somatic embryogenesis in Cotton. Int J Mol Sci. 2019;20:2070

56. Zhang XL, Wang YL, Yan YY, Peng H, Long Y, Zhang YC, Jiang Z, Liu P, Zou $C Y$, Peng HW, Pan GT, Shen YO. Transcriptome sequencing analysis of maize embryonic callus during early redifferentiation. BMC Genomics. 2019;20:159.

57. Olivares-García CA, Mata-Rosas M, Peña-Montes C, Quiroz-Figueroa F, Segura-Cabrera A, Shannon LM, Loyola-Vargas VM, Monribot-Villanueva JL, Elizalde-Contreras JM, Ibarra-Laclette E, Ramirez-Vázquez M, Guerrero-Analco JA, Ruiz-May E. Phenylpropanoids are connected to cell wall fortification and stress tolerance in avocado somatic embryogenesis. Int J Mol Sci. 2020; 21:5679.

58. Zhai LL, Xu L, Wang Y, Zhu XW, Feng HY, Li C, Luo XB, Everlyne M, Liu L. Transcriptional identification and characterization of differentially expressed genes associated with embryogenesis in radish (Raphanus sativus L.). Sci Rep. 2016;6:21652-64.

59. Xu Z, Zhang C, Zhang X, Liu C, Wu Z, Yang Z, Zhou K, Yang X, Li F. Transcriptome profiling reveals auxin and cytokinin regulating somatic embryogenesis in different sister lines of cotton cultivar CCRI24. J Integr Plant Biol. 2013;55:631-42.

60. Navarro BV, Elbl P, De Souza AP, Jardim V, de Oliveira LF, Macedo AF. dos Santos ALW, Buckeridge MS, Floh EIS. Carbohydrate-mediated responses during zygotic and early somatic embryogenesis in the endangered conifer, Araucaria angustifolia. PLoS One. 2017;12:e0180051.

61. Smeekens S, Ma J, Hanson J, Rolland F. Sugar signals and molecular networks controlling plant growth. Curr Opin Plant Biol. 2010;13:273-8.

62. Schuller $\mathrm{A}$, Reuther $\mathrm{G}$. Response of Abies alba embryonal-suspensor mass to various carbohydrate treatments. Plant Cell Rep. 1993;12:199-202.

63. Lipavská $\mathrm{H}$, Konrádová $\mathrm{H}$. Somatic embryogenesis in conifers: the role of carbohydrate metabolism. In Vitro Cell Dev. 2004;40:23-30.

64. Businge E, Bygdell J, Wingsle G, Moritz T, Egertsdotter U. The effect of carbohydrates and osmoticum on storage reserve accumulation and germination of Norway spruce somatic embryos. Physio Plant. 2013;149:273.

65. LipavskaÂ H, KonraÂdovaÂ H. Somatic embryogenesis in conifers: the role of carbohydrate metabolism. In Vitro Cell Dev Biol Plant. 2004;40:23-30.

66. Iraqi D, Tremblay FM. Analysis of carbohydrate metabolism enzymes and cellular contents of sugars and proteins during spruce somatic embryogenesis suggests a regulatory role of exogenous sucrose in embryo development. J Exp Bot. 2001;52:2301-11.

67. Hudec L, KonraÂdovâA H, HasilkovaÂ A, LipavskaÂ H. Norway spruce embryogenesis: changes in carbohydrate profile, structural development and response to polyethylene glycol. Tree Physiol. 2016;36:548-61.

68. Yang F, Wang Q, Schmitz G, Muller D, Theres K. The bHLH protein ROX acts in concert with RAX1 and LAS to modulate axillary meristem formation in Arabidopsis. Plant J. 2012;71:61-70.

69. Zhao Z, Andersen SU, Ljung K, Dolezal K, Miotk A, Schultheiss SJ, Lohmann JU. Hormonal control of the shoot stem-cell niche. Nature. 2010;465:1089-92.

70. Su YH, Zhang XS. Auxin gradients trigger de novo formation of stem cells during somatic embryogenesis. Plant Signal Behav. 2014;4:574-6.

71. Vondráková Z, Eliášová $\mathrm{K}$, Fischerová L, Vágner $\mathrm{M}$. The role of auxins in somatic embryogenesis of Abies alba. Cent Eur J Biol. 2011;6:587-96.

72. Michalczuk L, Ribnicky DM, Cooke TJ, Cohen JD. Regulation of Indole-3-acetic acid biosynthetic pathways in carrot cell cultures. Plant Physiol. 1992;100:1346-53.

73. Ribnicky DM, llic N, Cohen JD, Cooke TJ. The effects of exogenous auxins on endogenous indole-3-acetic acid metabolism (the implications for carrot somatic embryogenesis). Plant Physiol. 1996;112:549-58.

74. Thomas C, Bronner R, Molinier J, Prinsen E, van Onckelen H, Hahne G. Immuno-cytochemical localization of indole-3-acetic acid during induction of somatic embryogenesis in cultured sunflower embryos. Planta. 2002;215: 577-83.

75. Goldental-Cohen S, Israeli A, Ori N, Yasuor H. Auxin response dynamics during wild-type and entire flower development in tomato. Plant Cell Physiol. 2017:58:1661-72.

76. Guilfoyle TJ, Hagen G. Auxin response factors. Curr Opin Plant Biol. 2007;10: 453-60.

77. Abel S, Nguyen MD, Theologis A. The PS-IAA4/5-like family of early Auxininducible mRNAs in Arabidopsis thaliana. J Mol Biol. 1995;251:533-49.

78. Abel S, Oeller PW, Theologis A. Early auxin-induced genes encode shortlived nuclear proteins. Proc Natl Acad Sci. 1994;91:326-30.

79. Dreher KA, Brown J, Saw RE, Callis J. The Arabidopsis Aux/IAA protein family has diversified in degradation and auxin responsiveness. Plant Cell. 2006;18: 699-714.

80. Weijers D, Benkova E, Jäger KE, Schlereth A, Hamann T, Kientz M, Wilmoth JC, Reed JW, Jürgens $G$. Developmental specificity of auxin response by pairs of ARF and AuX/IAA transcriptional regulators. EMBO J. 2005;24:1874-85.

81. Parry G, Calderon-Villalobos LI, Prigge M, Peret B, Dharmasiri S, Itoh $\mathrm{H}_{\text {, }}$ Lechner E, Gray WM, Bennett M, Estelle M. Complex regulation of the TIR1/ AFB family of auxin receptors. Proc Natl Acad Sci. 2009;106:22540-5.

82. Tan X, Calderon-Villalobos LIA, Sharon M, Zheng C, Robinson CV, Estelle M, Zheng N. Mechanism of auxin perception by the TIR1 ubiquitin ligase. Nature. 2007:446:640-5. 
83. Overvoorde PJ, Okushima Y, Alonso JM, Chan A, Chang C, Ecker JR, Hughes B, Liu A, Onodera C, Quach H, Smith A, Yu G, Theologis A. Functional genomic analysis of the AUXIN/INDOLE-3-ACETIC ACID gene family members in Arabidopsis thaliana. Plant Cell. 2005;17:3282

84. Yu H, Soler M, Clemente H, Mila I, Paiva JAP, Myburg AA, Bouzayen M, Grima-Pettenati J, Cassan-Wang $H$. Comprehensive genome-wide analysis of the Aux/IAA gene family in eucalyptus: Evidence for the role of EgrlAA4 in wood formation. Plant Cell Physiol. 2015;56:700-14.

85. Audran-Delalande C, Bassa C, Mila I, Regad F, Zouine M, Bouzayen M. Genome-wide identification, Functional analysis and expression profiling of the Aux/IAA gene family in tomato. Plant Cell Physiol. 2012;53:659-72.

86. Gan D, Zhuang D, Ding F, Yu Z, Zhao Y. Identification and expression analysis of primary auxin-responsive Aux/IAA gene family in cucumber (Cucumis sativus). J Genet. 2013;92:513-21.

87. Kalluri UC, DiFazio SP, Brunner AM, Tuskan GA. Genome-wide analysis of Aux/IAA and ARF gene families in Populus trichocarpa. BMC Plant Biol. 2007; 7:59.

88. Ludwig Y, Zhang Y, Hochholdinger F. The maize (Zea mays L.) AUXIN/ INDOLE-3-ACETIC ACID gene family: Phylogeny, synteny, and unique roottype and tissue-specific expression patterns during development. PLoS One. 2013;8:e78859.

89. Jain M, Kaur N, Garg R, Thakur JK, Tyagi AK, Khurana JP. Structure and expression analysis of early auxin-responsive Aux/IAA gene family in rice (Oryza sativa). Funct Integr Genom. 2006;6:47-59.

90. Wu W, Liu Y, Wang Y, Li H, Liu J, Tan J, He J, Bai J, Ma H. Evolution analysis of the Aux/IAA gene family in plants shows dual origins and variable nuclear localization signals. Int J Mol Sci. 2017;18:2107.

91. Ren H. Gray WM. SAUR proteins as effectors of hormonal and environmental signals in plant growth. Mol Plant. 2015;8:1153-64.

92. Kant S, Bi Y, Zhu T. Rothstein SJ. SAUR39, a small Auxin-up RNA gene, acts as a negative regulator of Auxin synthesis and transport in Rice. Plant Physiol. 2009;151:691-701.

93. Khan S, Stone JM. Arabidopsis thaliana GH3.9 influences primary root growth. Planta. 2007;226(1):21-34.

94. Pierdonati E, Unterholzner SJ, Salvi E, Svolacchia N, Bertolotti G, loio RD, Sabatini S, Mambro RD. Cytokinin-dependent control of GH3 group II family genes in the Arabidopsis root. Plants (Basel). 2019;8:94.

95. Blanc G, Michaux-Ferrière N, Teisson C, Lardet L, Carron MP. Effects of carbohydrate addition on the induction of somatic embryogenesis in Hevea brasiliensis. Plant Cell Tissue Organ Cult. 1999;59:103-12.

96. Linkies A, Leubner-Metzger G. Beyond gibberellins and abscisic acid: how ethylene and jasmonates control seed germination. Plant Cell Rep. 2012;31: 253-70.

97. Li QF, Zhang SG, Wang JH. Transcriptome analysis of callus from Picea Balfouriana. BMC Genomics. 2014;15:553.

98. Tripathi P, Rabara RC, Rushton PJ. A systems biology perspective on the role of WRKY transcription factors in drought responses in plants. Planta. 2014; 239:255-66.

99. Lagace M, Matton DP. Characterization of a WRKY transcription factor expressed in late torpedo-stage embryos of Solanum chacoense. Planta. 2004;219:185-9.

100. Perry SE, Zheng QL, Zheng YM. Transcriptome analysis indicates that GmAGAMOUS-Like 15 may enhance somatic embryogenesis by promoting a dedifferentiated state. Plant Signal Behav. 2016;11:e1197463.

101. Yang $Y$, Wang N, Zhao S. Functional characterization of a WRKY family gene involved in somatic embryogenesis in Panax ginseng. Protoplasma. 2020; 257:449-58

102. Cominelli E. Tonelli C. A new role for plant R2R3-MYB transcription factors in cell cycle regulation. Cell Res. 2009;19:1231-2.

103. Huang C, Hu G, Li F, Li Y, Wu J, Zhou X. NbPHAN, a MYB transcriptional factor, regulates leaf development and affects drought tolerance in Nicotiana benthamiana. Physiol Plant. 2013;149:297-09.

104. Cai H, Tian S, Dong H, Guo C. Pleiotropic effects of TaMYB3R1 on plant development and response to osmotic stress in transgenic Arabidopsis. Gene. 2015;558:227-34.

105. Oh JE, Kwon Y, Kim JH, Noh H, Hong SW, Lee H. A dual role for MYB60 in stomatal regulation and root growth of Arabidopsis thaliana under drought stress. Plant Mol Biol. 2011;77:91-103.

106. Shin R, Burch AY, Huppert KA, Tiwari SB, Murphy AS, Guilfoyle TJ, Schachtman DP. The Arabidopsis transcription factor MYB77 modulates auxin signal transduction. Plant Cell. 2007;19:2440-53.
107. Tsuwamoto R, Yokoi S, Takahata Y. Arabidopsis EMBRYOMAKER. Encoding an AP2 domain transcription factor plays a key role in developmental change from vegetative to embryonic phase. Plant Mol Biol. 2010;73:481-92.

108. El Ouakfaoui S, Schnell J, Abdeen A, Colville A, Labbe H, Han S, Baum B, Laberge S, Miki B. Control of somatic embryogenesis and embryo development by AP2 transcription factors. Plant Mol Biol. 2010;74:313-26.

109. Heidmann I, de Lange B, Lambalk J, Angenent GC, Boutilier K. Efficient sweet pepper transformation mediated by the BABY BOOM transcription factor. Plant Cell Rep. 2011:30:1107-15.

110. Florez SL, Erwin RL, Maximova SN, Guiltinan MJ, Curtis WR. Enhanced somatic embryogenesis in Theobroma cacao using the homologous BABY BOOM transcription factor. BMC Plant Biol. 2015;15:121.

111. Zhou J, Li F, Wang JL, Ma Y, Chong K, Xu YY. Basic helix-loop-helix transcription factor from wild rice $(\mathrm{OrbHLH} 2)$ improves tolerance to salt and osmotic stress in Arabidopsis. J Plant Physiol. 2009;166:1296-306.

112. Zhang LY, Bai MY, Wu J, Zhu JY, Wang H, Zhang Z, Wang W, Sun Y, Zhao J, Sun XH, Yang HJ, Xu YY, Kim SH, Fujioka S, Lin WH, Chong K, Lu TG, Wang $\mathrm{ZY}$. Antagonistic HLH/bHLH transcription factors mediate brassinosteroid regulation of cell elongation and plant development in rice and Arabidopsis. Plant Cell. 2009;21:3767-80.

113. Chandler JW, Cole M, Flier A, Werr W. BIM1, a bHLH protein involved in brassinosteroid signalling, controls Arabidopsis embryonic patterning via interaction with DORNROSCHEN and DORNROSCHEN-LIKE. Plant Mol Biol. 2009;69:57-68.

114. Hecht V, Vielle-Calzada JP, Hartog MV, Schmidt ED, Boutilier K, Grossniklaus U, de Vries SC. The Arabidopsis SOMATIC EMBRYOGENESIS RECEPTOR KINA SE 1 gene is expressed in developing ovules and embryos and enhances embryogenic competence in culture. Plant Physiol. 2001;127:803-16.

115. Somleva MN, Schmidt EDL, de Vries SC. Embryogenic cells in Dactylis glomerata L. (Poaceae) explants identified by cell tracking and by SERK expression. Plant Cell Rep. 2000;19:718-26.

116. Zhang SZ, Liu XG, Lin YA, Xie GN, Fu FL, Liu HL, Wang J, Gao SB, Lan H, Rong TZ. Characterization of a ZmSERK gene and its relationship to somatic embryogenesis in a maize culture. Plant Cell Tiss Org Cult. 2011;105:29-37.

117. Singla B, Khurana JP, Khurana P. Characterization of three somatic embryogenesis receptor kinase genes from wheat, Triticum aestivum. Plant Cell Rep. 2008;27:833-43.

118. Yang $X$, Zhang $X$. Regulation of somatic embryogenesis in higher plants. Crit Rev Plant Sci. 2010;29:36-57.

119. Liu Y, Xie L, Liang X, Zhang S. CpLEA5, the late embryogenesis abundant protein gene from Chimonanthus praecox, possesses low temperature and osmotic resistances in prokaryote and eukaryotes. Int J Mol Sci. 2015;16:26978-90.

120. Kouzarides T. Chromatin modifications and their function. Cell. 2007;128: 693-705.

121. Allis $C D$, Jenuwein $T$. The molecular hallmarks of epigenetic control. Nat Rev Genet. 2016:17:487-500.

122. Black JC, Van Rechem C, Whetstine JR. Histone lysine methylation dynamics: establishment, regulation, and biological impact. Mol Cell 2012; 48: 491-507.

123. Earley KW, Shook MS, Brower-Toland B, Hicks L, Pikaard CS. In vitro specificities of Arabidopsis co-activator histone acetyltransferases: implications for histone hyperacetylation in gene activation. Plant J. 2007;52:615-26.

124. Wójcikowska B, Wójcik AM, Gaj MD. Epigenetic regulation of auxin-induced somatic embryogenesis in plants. Int J Mol Sci. 2020;21:2307.

125. Mozgova I, Köhler C, Hennig L. Keeping the gate closed: Functions of the polycomb repressive complex PRC2 in development. Plant J. 2015;83:121-32.

126. Perrella G, Consiglio MF, Aiese-Cigliano R, Cremona G, Sanchez-Moran E, Barra L, Errico A, Bressan RA, Franklin FCH, Conicella C. Histone hyperacetylation affects meiotic recombination and chromosome segregation in Arabidopsis. Plant J. 2010;62:796e806.

127. Deng W, Liu C, Pei Y, Deng X, Niu L, Cao X. Involvement of the histone acetyltransferase AtHAC1 in the regulation of flowering time via repression of FLOWERING LOCUS C in Arabidopsis. Plant Physiol. 2007;143:1660-8.

128. Li HL, Long Q, Guo D, Wang Y, Zhu JH, Peng SQ. Histone deacetylase interacts with a WRKY transcription factor to regulate the expression of the small rubber particle protein gene from Hevea brasiliensis. Ind Crops Prod. 2020;145:111989.

129. Kestler HA, Müller A, Gress TM, Buchholz M. Generalized venn diagrams: a new method of visualizing complex genetic set relations. Bioinformatics. 2004;21:1592-5.

130. Kolde R. pheatmap: Pretty Heatmaps. https://cran.r-project.org/web/ packages/ pheatmap/index.html. 2015. 
131. Li HL, Guo D, Yang ZP, Tang X, Peng SQ. Genome-wide identification and characterization of WRKY gene family in Hevea brasiliensis. Genomics. 2014; 104:14-23.

132. Livak KJ, Schmittgen TD. Analysis of relative gene expression data using real-time quantitative PCR and the $2^{-\Delta \Delta C T}$ method. Methods. 2001;25:402-8.

133. Quirk TJ, Quirk MH, Horton HF. One-way analysis of variance (ANOVA). In book: Excel 2019 for Biological and Life Sciences. Statistics. 2020:169-85.

\section{Publisher's Note}

Springer Nature remains neutral with regard to jurisdictional claims in published maps and institutional affiliations.

Ready to submit your research? Choose BMC and benefit from:

- fast, convenient online submission

- thorough peer review by experienced researchers in your field

- rapid publication on acceptance

- support for research data, including large and complex data types

- gold Open Access which fosters wider collaboration and increased citations

- maximum visibility for your research: over $100 \mathrm{M}$ website views per year

At BMC, research is always in progress.

Learn more biomedcentral.com/submissions 